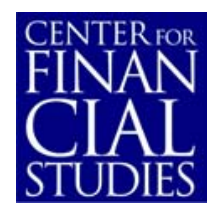

No. $2005 / 09$

\title{
Assessing Central Bank Credibility During the ERM Crises: Comparing Option and Spot Market-Based Forecasts
}

Markus Haas, Stefan Mittnik, and Bruce Mizrach 


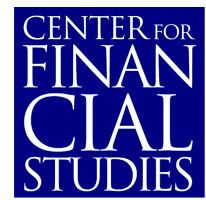

\section{Center for Financial Studies}

The Center for Financial Studies is a nonprofit research organization, supported by an association of more than 120 banks, insurance companies, industrial corporations and public institutions. Established in 1968 and closely affiliated with the University of Frankfurt, it provides a strong link between the financial community and academia.

The CFS Working Paper Series presents the result of scientific research on selected topics in the field of money, banking and finance. The authors were either participants in the Center's Research Fellow Program or members of one of the Center's Research Projects.

If you would like to know more about the Center for Financial Studies, please let us know of your interest.

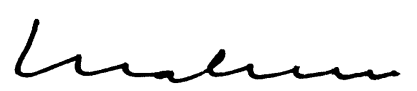

Prof. Dr. Jan Pieter Krahnen

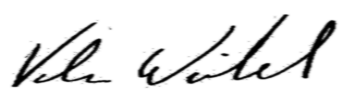

Prof. Volker Wieland, Ph.D. 


\title{
Assessing Central Bank Credibility During the ERM Crises: Comparing Option and Spot Market-Based Forecasts*
}

\author{
Markus Haas ${ }^{1}$, Stefan Mittnik ${ }^{2}$, \\ and Bruce Mizrach ${ }^{3}$ \\ First Version: October 2004 \\ This Version: February 2005
}

\begin{abstract}
:
Financial markets embed expectations of central bank policy into asset prices. This paper compares two approaches that extract a probability density of market beliefs. The first is a simulatedmoments estimator for option volatilities described in Mizrach (2002); the second is a new approach developed by Haas, Mittnik and Paolella (2004a) for fat-tailed conditionally heteroskedastic time series. In an application to the 1992-93 European Exchange Rate Mechanism crises, that both the options and the underlying exchange rates provide useful information for policy makers.
\end{abstract}

\section{JEL Classification: G12, G14, F31}

Keywords: Options; Implied Probability Densities; GARCH; Fat-tails; Exchange Rate Mechanism.

\footnotetext{
* The research of Haas and Mittnik was supported by a grant from the Deutsche Forschungsgemeinschaft. Mittnik conducted part of the research while visiting the Department of Economics at Washington University in St. Louis with a grant from the Fulbright Commission. This paper was prepared for the 2004 JFS-Carli Bank of Italy Conference on Derivatives and Financial Stability. We thank our discussant Paul Wachtel for his valuable comments.

${ }^{1}$ University of Munich

2 University of Munich

3 Rutgers University

Direct editorial correspondence to the third author at e-mail: mizrach@econ.rutgers.edu, (732) 932-8261

(voice) and (732) 932-7416 (fax). http://snde.rutgers.edu
} 


\section{Introduction}

A basic insight of financial economics is that asset prices should reflect views about the future. For this reason, many economists rely on market prices to make predictions. Even when these views are incorrect, policy makers may want to avoid changes that the market is not expecting.

In recent years, some novel techniques have been introduced to extract market expectations. This paper explores two of them: extracting implied probability densities from option prices and volatility modeling of the underlying. Both methods have the advantage of producing predictive densities rather than just point forecasts. These tools can, in principal, allow central bankers to examine the full range of risks facing their economies.

There are numerous approaches that generalize the Black-Scholes model. Merton (1976) and Bates (1991) allow sudden changes in the level of asset prices. Wiggins (1987), Hull and White (1987), Stein and Stein (1991), and Heston (1993) allow volatility to change over time. A related literature, with papers by Dumas, Fleming and Whaley (1998) and Das and Sundaram (1999), has looked at deterministic variations in volatility with the level of the stock price or with time.

To extract market expectations of the exchange rate, we utilize a method first used in Mizrach (2002) that looks directly at the probability distribution. We parameterize the exchange rate process as a mixture of log normals, as in Ritchey (1990) and Melick and Thomas (1997), and fit the model to options prices. In an application to the Enron bankruptcy, Mizrach found that investors were far too optimistic about Enron until days before the stock's collapse.

Our second approach tries to extract information directly from the underlying currencies. We utilize a general mixture of two normal densities to extract information from the spot foreign exchange market. In this model, both the mixing weights as well as the parameters of the component densities, i.e., component means and variances, are time-varying and may depend on past exchange rates as well as further explanatory variables, such as interest rates. The dynamic mixture model we specify is a combination of the logistic autoregressive mixture with exogenous variables, or LMARX, model investigated in Wong and Li (2001) and the mixed normal GARCH process recently proposed by Haas, Mittnik and Paolella (2004a). The predictive densities generated from the resulting LMARX-GARCH model exhibit an enormous flexibility, and they may be multimodal, for example, in times where a realignment becomes more probable.

In this paper, we utilize the two approaches to explore market sentiment prior to the exchange rate crises of September 1992 and July-August 1993. In the first episode, the British Pound (BP) 
and Italian Lira withdrew from the Exchange Rate Mechanism (ERM) of the European Monetary System (EMS). The Pound had traded in a narrow range against the German Deutsche Mark (DM) for almost two years and the Lira for more than five. The crisis threw the entire plan for European economic and financial integration into turmoil. The French Franc (FF) remained in the mechanism, but speculative pressures against it remained strong. In the second crisis we examine, the Franc, in August 1993, had to abandon its very close link with the DM (the "Franc fort") and widen it's fluctuation band.

Campa and Chang (1996) have looked at ERM credibility using arbitrage bounds on option prices. They find that option prices reflected the declining credibility of the Lira and Pound in 1992 and the Franc in 1993. Malz (1996) finds an increasing risk of BP devaluation starting in late August 1992. Christoffersen and Mazzotta (2004) find useful predictive information in ten European countries' over-the-counter currency options.

We first examine the options markets' implied probability of depreciation in the FF and BP prior to the ERM crises. The model estimates reveal that the market anticipated both events. The devaluation risk with the Franc rises significantly 11 days in advance of the crisis. With the Pound, the risk is subdued until only five days before it devalued on "Black Wednesday" September 16, 1992.

Vlaar and Palm (1993) were the first to use the normal mixture density to model EMS exchange rates against the DM, noting that, in contrast to freely floating currencies, these often show pronounced skewness, due to jumps which occur in case of realignments, but also, for example, as a result of expected policy changes or speculative attacks. Although Vlaar and Palm (1993) noted that making the jump probability a function of explanatory variables, such as inflation and interest rates, may be a promising task, they did not undertake such analysis.

Neely (1994) surveys research on forecasting realignments in the EMS and reports evidence for realignments to be predictable to some extent from information such as interest rates and the position of the exchange rate within the band. Building both on the results surveyed in Neely (1994) and the work of Vlaar and Palm (1993) and Palm and Vlaar (1997), the studies of Bekaert and Gray (1998), Neely (1999) and Klaster and Knot (2002) use more general dynamic mixture models of exchange rates in target zones. Thus, the model employed below has some similarities with those developed in these studies, as will be discussed below.

The dynamic mixture model provides, as in the options-based approach, estimates of the 
probability of a depreciation. For the FF, the model indicates a considerable increase of this probability one week in advance of the crisis, and a further increase immediately before the de facto devaluation of the FF, when the bands of the target zone were widened to $\pm 15 \%$.

For the BP, we can, in contrast to the options-based approach, not develop a promising dynamic mixture model, because the BP joined the ERM only in October 1990 and withdrew in September 1992. During this period there were no realignments or large jumps within the band, so that the sample does not provide information that is necessary to fit a target zone mixture model. Consequently, the mixed normal GARCH model detects a rise in the devaluation probability only after the Pound was withdrawn from the ERM.

Both models provide a complete predictive density for the exchange rate, and the last part of the paper examines the fit of the entire density. We utilize the approach of Berkowitz (2001) to formally compare the model's density-forecasting performance. In the options market, the predictive density becomes indistinguishable from the post crisis density on July 21 for the FF, 11 days before the crisis. For the BP, there are some early warning signals in mid-August and the beginning of September. In the FF spot market, the predictive density is consistent with the post-crisis data from the outset. For the BP, the result is similar to the options. There are some brief early signals, but the densities statistically differ from the post-devalation period until September 10th.

The paper continues with some discussion of the ERM. Section 3 describes the theory of implied density extraction from options. It also proposes a mixture of log normals specification which nests the Black-Scholes model. We also develop a GARCH mixture model for the spot exchange rate. Section 4 contains some stylized features of the currency options, and some detailed issues in estimation for both models. From the two sets of parameter estimates, we compute implied devaluation probabilities. Section 5 compares the entire predictive density statistically. Section 6 concludes with directions for future research.

\section{The ERM}

The ERM began in 1979 with seven member countries. ${ }^{1}$ The mechanism included a grid of fixed exchange rates with European Currency Unit (ECU) central parities and fluctuation bands. Prior to the crises, the $\mathrm{FF}$ had a target zone of $\pm 2.25 \%$ and the $\mathrm{BP} \pm 6 \%$. Maintaining the parities

${ }^{1}$ Belgium, Denmark, France, Germany, Italy, Ireland, and the Netherlands. 
required policy coordination with the German Bundesbank, and when necessary, intervention.

By the Spring of 1992, the momenta towards a single European currency seemed irreversible. Spain had joined the ERM in June of 1989. Great Britain finally overcame its resistance in October 1990. Portugal joined in April 1992 bringing the total membership to ten. In addition, Finland and Sweden had been following indicative DM targets. All the major European currencies, save the Swiss Franc, were incorporated in a system of apparently stable exchange rate bands. Almost five years had passed without devaluations. ${ }^{2}$ The financial sector seemed poised for monetary union, the next logical step in the blueprint of the Maastricht treaty signed on December 10, 1991.

A swift sequence of events left the idea of currency union almost irretrievably damaged. The Danes rejected the Maastricht treaty in June of 1992. The Finnish Markaa and the Swedish Krona faced devaluation pressures in August which the Bank of Finland and the Swedish Riksbank actively resisted. The Markaa was allowed to float on September 8, and it quickly devalued 15\% against the DM. The Riksbank raised their marginal lending rate to $500 \%$ on September 16.

Then some of the core ERM currencies came under speculative attack. The Bank of England briefly raised their base lending rates, but the British chose to withdraw from the ERM on September 16 rather than expending additional reserves. ${ }^{3}$ The Lira devalued by $7 \%$ on September 13 and withdrew from the mechanism on September 17.

A number of additional devaluations followed. The Krona was allowed to float on November 19. The Spanish Peseta (in September and November 1992), the Portuguese Escudo (in November 1992), and then the Irish Punt (in February 1993) subsequently adopted new parities. The ERM remained in turmoil into the summer. France faced continued pressure and went through a de facto devaluation when the ERM bands were widened to $\pm 15 \%$ on August 2, 1993 .

In retrospect, the origins of these crises were evident. The Finnish and Swedish economies were weakened by recession and the collapse of the Soviet Union. Britain had probably overvalued the Pound when it entered the ERM. The Lira had appreciated 30\% in real terms against the DM since 1987. Germany had raised interest rates to fight off inflationary pressures from unification, weakening the entire European economy in the process.

The folklore of this period suggests that some market participants anticipated the crisis, and may even have precipitated it. The hedge fund trader George Soros is rumored to have made some US $\$ 1$ billion speculating against the Pound and the Lira in 1992.

2 There was a small devaluation of the Italian Lira when it moved to narrow bands in January 1990.

3 The Bundesbank is reported to have spent DM92 billion defending the Pound and Lira during this crisis. 
The question we ask here is how well diffused was this information. Did either the options market or spot market anticipate these events and can our models extract these expectations?

\section{Models for Currency Options and the Spot Rate}

\subsection{Implied Probability Densities from Options}

The basic option pricing framework builds upon the Black-Scholes assumption that the underlying asset is $\log$ normally distributed. Let $f\left(S_{T}\right)$ denote the terminal risk neutral probability at time $T$, and let $F\left(S_{T}\right)$ denote the cumulative probability . A European call option at time $t$, expiring at $T$, with strike price $K$, is priced

$$
C(K, \tau)=e^{-i_{d} \tau} \int_{K}^{\infty}\left(S_{T}-K\right) f\left(S_{T}\right) d S_{T}
$$

where $\tau=T-t$, and $i_{d}$ and $i_{f}$ are the annualized domestic and foreign risk-free interest rates. In the case where $f(\cdot)$ is the log-normal density and volatility $\sigma$ is constant with respect to $K$, this yields the Black-Scholes formula,

$$
\begin{gathered}
B S\left(S_{t}, K, \tau, i_{f}, i_{d}, \sigma\right)=S_{t} e^{-i_{f} \tau} \Phi\left(d_{1}\right)-K e^{-i_{d} \tau} \Phi\left(d_{2}\right) \\
d_{1}=\frac{\ln \left(S_{t} / K\right)+\left(i_{d}-i_{f}+\sigma^{2} / 2\right) \tau}{\sigma \sqrt{\tau}} \\
d_{2}=d_{1}-\sigma \sqrt{\tau}
\end{gathered}
$$

where $\Phi(\cdot)$ denotes the cumulative standard normal distribution. In this benchmark case, implied volatility is a sufficient statistic for the entire implied probability density which is centered at the risk-free interest differential $i_{d}-i_{f}$.

Mizrach (2002) surveys an extensive literature and finds that option prices in a variety of markets appear to be inconsistent with the Black-Scholes assumptions. In particular, volatility seems to vary across strike prices - often with a parabolic shape called the volatility "smile." The smile is often present on only one part of the distribution giving rise to a "smirk."

\subsubsection{How Volatility Varies with the Strike}

Under basic no-arbitrage restrictions, we can consider more general densities than the log-normal for the underlying. Breeden and Litzenberger (1978) show that the first derivative is a function of the cumulative distribution,

$$
\partial C /\left.\partial K\right|_{K=S_{T}}=-e^{-i_{d} \tau}\left(1-F\left(S_{T}\right)\right) .
$$


The second derivative then extracts the density,

$$
\partial^{2} C /\left.\partial K^{2}\right|_{K=S_{T}}=e^{-i_{d} \tau} f\left(S_{T}\right)
$$

The principal problem in estimating $f$ is that we do not observe a continuous function of option prices and strikes. Early attempts in the literature, like Shimko (1993), simply interpolated between option prices. Bliss and Panigirtzoglou (2002) find that implied volatility functions fit well when the strikes are dense, but as Mizrach (2002) notes, this often leads to arbitrage violations in the tails. Later attempts turned to either specifying a density family for $f$ or a more general stochastic process for the spot price. Dupire (1994) shows that both approaches are equivalent; for driftless diffusions, there is a unique stochastic process corresponding to a given implied probability density. This paper follows Ritchey (1990) and Melick and Thomas (1997) by specifying $f$ as a mixture of log normal distributions. The advantage of this specification is that the option prices are just probability weighted averages of the Black-Scholes prices for each mixture component.

\subsubsection{Mixture-of-Log-Normals Specification}

We assume that the stock price process is a draw from a mixture of three (non-standard) normal distributions, $\Phi\left(\mu_{j}, \sigma_{j}\right), j=1,2,3$, with $\mu_{3} \geq \mu_{2} \geq \mu_{1}$. Three additional parameters $\lambda_{1}, \lambda_{2}$ and $\lambda_{3}$ define the probabilities of drawing from each normal. To nest the Black-Scholes, we restrict the mean to equal the interest differential, $\mu_{2}=i_{d}-i_{f}$. Risk neutral pricing then implies restrictions on either the other means or the probabilities. We chose to let $\mu_{1}, \lambda_{1}$ and $\lambda_{3}$ vary, which implies

and

$$
\mu_{3}=\frac{\mu_{1} \lambda_{1}}{\lambda_{3}}
$$

$$
\lambda_{2}=1-\lambda_{1}-\lambda_{3}
$$

For estimation purposes, this leaves six free parameters $\theta=\left(\theta_{1}, \theta_{2}, \ldots, \theta_{6}\right)$. We take exponentials of all the parameters because they are constrained to be positive. The left-hand mixture is given by

$$
\Phi\left(\mu_{1}, \sigma_{1}\right)=\Phi\left(i_{d}-i_{f}-e^{\theta_{1}}, 100 \times e^{\theta_{2}}\right) .
$$

The only free parameter of the middle normal density is the standard deviation,

$$
\Phi\left(\mu_{2}, \sigma_{2}\right)=\Phi\left(i_{d}-i_{f}, 100 \times e^{\theta_{3}}\right) .
$$


We use the logistic function for the probabilities to bound them on $[0,1]$,

$$
\begin{aligned}
& \lambda_{1}=\frac{e^{\theta_{4}}}{1+e^{\theta_{4}}}, \\
& \lambda_{3}=\frac{e^{\theta_{5}}}{1+e^{\theta_{5}}} .
\end{aligned}
$$

The probability specification implies the following mean restrictions on the third normal,

$$
\Phi\left(\mu_{3}, \sigma_{3}\right)=\Phi\left(\left(i_{d}-i_{f}+e^{\theta_{1}}\right) \times \frac{e^{\theta_{4}} /\left(1+e^{\theta_{4}}\right)}{e^{\theta_{5}} /\left(1+e^{\theta_{5}}\right)}, 100 \times e^{\theta_{6}}\right) .
$$

Mizrach (2002) shows that this data generating mechanism can match a wide range of shapes for the volatility smile.

\subsection{GARCH Mixture Model for the Spot Exchange Rate}

The mixed normal GARCH process is the building block of our models for the spot rate. ${ }^{4}$ It was recently proposed by Haas, Mittnik and Paolella (2004a) and generalizes the classic normal GARCH model of Bollerslev (1986) to the mixture setting. The percentage change of the logexchange rate, $r_{t}=100 \times \log \left(S_{t} / S_{t-1}\right)$, where $S_{t}$ is the exchange rate at time $t$, is said to follow a $k$-component mixed normal $(\mathrm{MN}) \operatorname{GARCH}(p, q)$ process if the conditional distribution of $r_{t}$ is a $k$-component MN, that is,

$$
r_{t} \mid \Psi_{t-1}=M N\left(\lambda_{1, t}, \ldots, \lambda_{k, t}, \mu_{1, t}, \ldots, \mu_{k, t}, \sigma_{1, t}^{2}, \ldots, \sigma_{k, t}^{2}\right),
$$

where $\Psi_{t}$ is the information at time $t$, and the mixing weights sastisfy $\lambda_{j} \in(0,1), j=1, \ldots, k$, and $\sum_{j} \lambda_{j}=1$. The $k \times 1$ vector of component variances, denoted by $\sigma_{t}^{(2)}=\left[\sigma_{1, t}^{2}, \ldots, \sigma_{k, t}^{2}\right]^{\prime}$, evolves according to

$$
\sigma_{t}^{(2)}=\alpha_{0}+\sum_{i=1}^{q} \alpha_{i} \epsilon_{t-i}^{2}+\sum_{i=1}^{p} \beta_{i} \sigma_{t-i}^{(2)},
$$

where $\alpha_{0}$ is a positive $k \times 1$ vector; $\alpha_{i}, i=1, \ldots, q$, are nonnegative $k \times 1$ vectors; and $\beta_{i}, i=1, \ldots, p$, are nonnegative $k \times k$ matrices, and

$$
\epsilon_{t}=r_{t}-E\left(r_{t} \mid \Psi_{t-1}\right)=r_{t}-\sum_{j=1}^{k} \lambda_{j, t} \mu_{j, t} .
$$

Haas, Mittnik and Paolella (2004a) considered the case where the mixing weights, $\lambda_{j, t}$, and the component means, $\mu_{j, t}, j=1, \ldots, k$, are constant over time, but the generalization considered in (12)-(14), with these quantities being time-varying, is straightforward conceptually. The mixing

\footnotetext{
${ }^{4}$ For an application of a related model class, the Markov-switching GARCH model, to predicting exchange
} rate densities, see Haas, Mittnik and Paolella (2004b). 
weights and the component means may depend both on lagged values of $r_{t}$ and on further explanatory variables, as in the LMARX model of Wong and Li (2001). Thus, the dynamic mixture model employed in the present paper is a combination of the MN-GARCH and the LMARX models, which will be termed LMARX-GARCH.

As with the classic GARCH model, the MN-GARCH(1,1) specification will usually be sufficient, and in most applications it will be reasonable to impose certain restrictions on the $\alpha_{i}$ 's and $\beta_{i}$ 's in (13). However, the general formulation will be useful in discussing different versions of the MN-GARCH process corresponding to different restrictions imposed on the parameters.

The conditional moments of the LMARX-GARCH model depend nonlinearly on the mixing weights and the parameters of the component densities. Their dynamics will thus be quite complicated. For example, the conditional mean is immediately seen to be the weighted average of the component means,

$$
\bar{\mu}_{t}:=E\left(r_{t} \mid \Psi_{t-1}\right)=\sum_{j=1}^{k} \lambda_{j, t} \mu_{j, t},
$$

while the conditional variance is

$$
\begin{aligned}
\bar{\sigma}_{t}^{2}:=\operatorname{Var}\left(r_{t} \mid \Psi_{t-1}\right) & =\sum_{j=1}^{k} \lambda_{j, t}\left(\sigma_{j, t}^{2}+\mu_{j t}^{2}\right)-\left(\sum_{j=1}^{k} \lambda_{j, t} \mu_{j, t}\right)^{2} \\
& =\sum_{j=1}^{k} \lambda_{j, t} \sigma_{j, t}^{2}+\sum_{j=1}^{k} \lambda_{j, t}\left(\mu_{j, t}-\bar{\mu}_{t}\right)^{2} \\
& =\sum_{j=1}^{k} \lambda_{j, t} \sigma_{j, t}^{2}+\frac{1}{2} \sum_{i=1}^{k} \sum_{j=1}^{k} \lambda_{i, t} \lambda_{j, t}\left(\mu_{i, t}-\mu_{j, t}\right)^{2} .
\end{aligned}
$$

Thus, the conditional variance is the weighted average of the component variances plus a term that measures the distance between the means of the mixture components. Note that the second term in (16) can be interpreted as the variance of the conditional mean. In the two-component model considered below, the term involving the means in (17) becomes $\lambda_{1, t}\left(1-\lambda_{1, t}\right)\left(\mu_{1, t}-\mu_{2, t}\right)^{2}$. The variance increases, for example, if the expected devaluation in case of a realignment is large. The coefficient of the squared distance between the means equals $\lambda_{1, t}\left(1-\lambda_{1, t}\right)$, which is the variance of the conditional Bernoulli distribution over the mixture components.

Due to the different histories of the currencies within the EMS, the conditional densities differ for the Franc and the Pound. We discuss the model for the Franc first and subsequently outline the modifications that are necessary for the Pound. 


\subsubsection{Conditional Density for the Franc}

We assume that the conditional density of the exchange rate return process, $r_{t}$, is a two-component normal mixture density, that is,

$$
f\left(r_{t} \mid \Psi_{t-1}\right)=\frac{\lambda_{t}}{\sigma_{1, t} \sqrt{2 \pi}} e^{\left\{-\frac{\left(r_{t}-\mu_{1, t}\right)^{2}}{2 \sigma_{1, t}^{2}}\right\}}+\frac{1-\lambda_{t}}{\sigma_{2, t} \sqrt{2 \pi}} e^{\left\{-\frac{\left(r_{t}-\mu_{2, t}\right)^{2}}{2 \sigma_{2, t}^{2}}\right\}},
$$

where information set $\Psi_{t-1}$ consists of the exchange rates as well as further explanatory variables, such as interest rates.

With probability $\lambda_{t}$, there is a jump in the exchange rate, due to a realignment or a relatively large movement within the target zone. As in Bekaert and Gray (1998) and Neely (1999), the mixing weight, or probability of a jump, $\lambda_{t}$, depends on the slope of the yield curve, $y c_{t}=i_{t}^{3}-i_{t}^{1}$, where $i_{t}^{3}$ and $i_{t}^{1}$ denote the three- and one-month interest rates, respectively. The functional relationship is specified in a logistic fashion. More specifically, we assume that

$$
\lambda_{t}=\frac{1}{1+e^{\gamma_{0}+\gamma_{1} y c_{t-1}^{\star}}},
$$

where $y c_{t}^{\star}=\operatorname{sign}\left(y c_{t}\right) \log \left(1+\left|y c_{t}\right|\right)$. We have also considered a probit specification in (19), where $\lambda_{t}=\Phi\left(\gamma_{0}+\gamma_{1} y c_{t-1}^{\star}\right)$, and $\Phi(z)=(2 \pi)^{-1 / 2} \int_{-\infty}^{z} e^{-\xi^{2} / 2} d \xi$, which is used in Mizrach (1995), Bekaert and Gray (1998), and Neely (1999). Here, for the data at hand, it leads to virtually the same relation between $\lambda_{t}$ and $y c_{t-1} \cdot{ }^{5}$ Beine and Laurent (2003) and Beine, Laurent, and Lecourt (2003) use the logistic specification in modeling returns of the US\$ against other major currencies, where the mixing weight depends on central bank interventions. In addition to using the probit specification, Bekaert and Gray (1998) and Neely (1999) work in terms of the untransformed variable $y c_{t}$, that is, they set $\lambda_{t}=\Phi\left(\gamma_{0}+\gamma_{1} y c_{t-1}\right){ }^{6}$ The motivation for our use of the contracting transformation $y c_{t}^{\star}$ is illustrated in the left panel of Figure 1, which plots $r_{t}$ against the once-lagged slope measures $y c_{t-1}$ and $y c_{t-1}^{\star}$, respectively, for the 172 monthly observations that form our estimation period. Obviously, using $y c_{t-1}$ directly, estimated relationships between $y c_{t-1}$ and the next period's density of $r_{t}$ will suffer from the single large "outlier" $\min \left\{y c_{t}\right\}=-40$.

5 A generalization of the probit approach to more than two mixture components is considered in Lanne and Saikkonen (2003).

6 Actually, Neely (1999) uses short-term interest rate differentials as a second explanatory variable. The latter and the slope of the yield curve are highly correlated, however, with a correlation coefficient of -0.8216 in our training sample. Engel and Hakkio (1996) let the transition probabilities in a Markov-switching model depend on the position of the exchange rate within its EMS band, but this did not lead to any improvement with our data. 


\section{[Insert Figure 1]}

The mean of the jump-component, $\mu_{1 t}$, is also assumed to depend on $y c_{t-1}$, namely

$$
\mu_{1, t}=\phi_{0}+\phi_{1} y c_{t-1}^{\star}
$$

The second mixture component in (18) represents the density of the exchange rate when the target zone is credible, so that, as in Neely (1999), it is plausible to let $\mu_{2, t}$ depend on the position of the exchange rate within the target zone. More specifically,

$$
\mu_{2, t}=\psi_{0}+\psi_{1}\left(S_{t-1}-P_{t-1}\right),
$$

where $P_{t}$ is the central parity at date $t$.

Finally, we discuss the conditional heteroskedasticity in the component variances $\sigma_{1, t}^{2}$ and $\sigma_{2, t}^{2}$. To do so, we reproduce the defining equation of the MN-GARCH process specified by Haas, Mittnik, and Paolella (2004a) for the two-component $\operatorname{GARCH}(1,1)$ case, where (13) is of the form

$$
\left[\begin{array}{l}
\sigma_{1, t}^{2} \\
\sigma_{2, t}^{2}
\end{array}\right]=\left[\begin{array}{l}
\alpha_{01} \\
\alpha_{02}
\end{array}\right]+\left[\begin{array}{l}
\alpha_{11} \\
\alpha_{12}
\end{array}\right] \epsilon_{t-1}^{2}+\left[\begin{array}{ll}
\beta_{11} & \beta_{12} \\
\beta_{21} & \beta_{22}
\end{array}\right]\left[\begin{array}{c}
\sigma_{1, t-1}^{2} \\
\sigma_{2, t-1}^{2}
\end{array}\right]
$$

with $\epsilon_{t}=r_{t}-E\left(r_{t} \mid \Psi_{t-1}\right)=r_{t}-\lambda_{t} \mu_{1, t}-\left(1-\lambda_{t}\right) \mu_{2, t}$. Vlaar and Palm (1993) assume that, for all $t$, the difference between $\sigma_{1, t}^{2}$ and $\sigma_{2, t}^{2}$ is equal to a constant jump size, $\delta^{2}$; that is, they restrict, in (22), $\alpha_{01}=\alpha_{02}+\delta^{2}, \alpha_{11}=\alpha_{12}, \beta_{12}=\beta_{22}$, and $\beta_{21}=\beta_{11}=0$, so that $\sigma_{1, t}^{2}=\sigma_{2, t}^{2}+\delta^{2}$ for all $t$. Vlaar and Palm (1993) argue that "this procedure is preferred to that of independent variances, since it seems reasonable to assume that the same GARCH effect is present in all variances." This specification is also adopted in Neely (1999) and Beine and Laurent (2003). We will, however, not use this for the Franc, but rather employ the restricted version of (22), termed "partial MNGARCH" in Haas, Mittnik, and Paolella (2004a), which sets $\alpha_{11}=0$, and $\beta_{11}=\beta_{12}=\beta_{21}=0$, so that $\sigma_{1, t}^{2}=\sigma_{1}^{2}=\alpha_{01}$ for all $t$. That is, only the variance in the "credibility regime" is driven by a GARCH process, while the variance in the jump component is constant. This specification seems more reasonable, given that, in a system of target zones, jumps are not expected to come clustered, so that a dynamic behavior of the jump component's variance would be difficult to interpret.

\subsubsection{Modifications for the Pound}

For the Pound, we use the model of the previous section with two modifications, which are enforced by the short duration of the Pound's membership in the EMS.

The first modification concerns the conditional mean in the second mixture component, given by (21). As we use monthly data from January 1978 to December 1991 to fit the model, there 
is no central parity for most of the data points. Thus, we replace (21) with a simple first-order autoregressive specification, i.e., for the BP (21) becomes

$$
\mu_{2, t}=\psi_{0}+\psi_{1} r_{t-1}
$$

Secondly, we use a different specification for the conditional heteroskedasticity. In the previous section, we argued for the partial MN-GARCH structure because the first mixture component was suited to capture large jumps in the exchange rate, particularly due to realignments, which do not come clustered. The pound, however, did not join the EMS before October 1990, and so, this argument is not valid for this currency. Instead, we treat the components symmetrically and assume a $\operatorname{GARCH}(1,1)$ process in both components, where, for parsimony, we adopt the restricted specification of Vlaar and Palm (1993), where both components are driven by the same GARCH process. That is, the first component's variance is given by $\sigma_{2, t}^{2}+\delta^{2}$, and ${ }^{7}$

$$
\sigma_{2, t}^{2}=\alpha_{02}+\alpha_{12} \epsilon_{t-1}^{2}+\beta_{22} \sigma_{2, t-1}^{2}
$$

describes the evolution of the variance in the second component.

\section{Data and Estimation Results}

\subsection{Options Market}

\subsubsection{Data}

The majority of the intra-ERM derivatives trading is in the over-the-counter markets, and the data is not generally available to non-traders. The best publicly available data are for US dollar (US\$) exchange rates which are traded in Philadelphia. We focus on the US Dollar/British Pound (US\$/BP) and Dollar/French Franc (US\$/FF) contracts. We have data for the years 1992 and 1993, which encompass both major ERM realignments.

The US\$ appears to be an adequate proxy for the DM. During September 1992, the DM depreciated by $-1.47 \%$ against the US\$, while the BP depreciated $-11.51 \%$. From July 1 to August 5, 1993, the DM was similarly stable, depreciating $-0.83 \%$, while the Franc devalued by $-3.59 \%$ against the US\$.

\footnotetext{
7 It is, of course, not necessarily the case that the first mixture component has the higher variance, as implied by this specification. This is not just a labelling problem and may be a serious restriction in general, because the component means are modeled differently. However, it is not restrictive for the present data, as we confirmed by switching the roles of $\sigma_{1, t}^{2}$ and $\sigma_{2, t}^{2}$.
} 
Both American ${ }^{8}$ and European options are traded. The BP options are for 31,250 Pounds, and the FF options are for 250,000 Francs. We use daily closing option prices that are quoted in cents. Spot exchange rates are expressed as US\$ per unit of foreign currency and are recorded contemporaneously with the closing trade. Foreign currency appreciation (depreciation) will increase the moneyness of a call (put) option. Interest rates are the Eurodeposit rates closest in maturity to the term of the option.

To obtain a rough idea about the implied volatility pattern in the currency options, we look at sample averages. We sort the data into bins based on the strike/spot ratio, $S / K$, and compute implied volatilities using the Black-Scholes formula. In Figures 2 and 3 and, we plot the data for all of 1992 and 1993, for the FF and BP, respectively. Both appear to display the characteristic pattern, with the minima of the implied volatility at the money, and with higher implied volatilities in the two tails.

[INSERT Figure 2]

[INSERT Figure 3]

For estimation purposes, we excluded options that were more than $10 \%$ in or out of the money and with volumes less than 5 contracts. This seemed to eliminate most data points with unreasonably high implied volatilities. For the Pound, we looked at options from 5 to 75 days to maturity. Because the data were thinner with the Franc, we utilized all maturities greater than 5 days.

We will now try to infer whether changes in the smile signalled an impending crisis in the ERM.

\subsubsection{Implied Density Estimation}

There are two key issues in fitting the model. The first is to extend the analysis to American options which can be exercised before expiration. The second is choosing the loss function for estimation.

We approximate American puts and calls using the Bjerksund and Stensland (1993) approach. Hoffman (2000) shows that the Bjerksund-Stensland algorithm compares favorably in accuracy and computational efficiency to the Barone-Adesi and Whaley (1987) quadratic approximation. Our estimates were also quite similar using implied binomial trees.

Because $f\left(S_{t}\right)$ is the risk neutral density and is not directly observable, we must find a way to

${ }^{8}$ Currency options may be thought of as options on a dividend paying stock where the dividend is equal to the foreign risk free rate. Early exercise is relevant for call options where the foreign risk free rate is high because this indicates that the currency is likely to devalue. The risk of devaluation will then be priced into American options of all maturities. 
treat the options prices as sample "moments". Let

$$
\left\{d_{j, t}\right\}_{j=1}^{n}=\left[c\left(\tau_{1}, K_{1}\right), \ldots, c\left(\tau_{m}, K_{m}\right), p\left(\tau_{m+1}, K_{m+1}\right), \ldots, p\left(\tau_{n}, K_{n}\right)\right]
$$

denote a sample of size $n$ of the calls $c$ and puts $p$ traded at time $t$, with strike price $K_{j}$ and expiring in $\tau_{j}$ years, and denote the pricing estimates from the model by $\left\{d_{j, t}(\theta)\right\}$.

In matching model to data, Christoffersen and Jacobs (2001) emphasize that the choice of loss function is important. Bakshi, Cao and Chen (1997), for example, match the model to data using option prices. This can lead to substantial errors among the low priced options though. Since these options are associated with tail probability events, this is not the best metric for our exercise. We obtained the best fit overall using the implied Bjerksund-Stensland implied volatility,

$$
\sigma_{j, t}=B J S T^{-1}\left(d_{j, t}, S_{t}, i_{t}\right) .
$$

Let the estimated volatility be denoted by

$$
\sigma_{j, t}(\theta)=B J S T^{-1}\left(d_{j, t}(\theta), S_{t}, i_{t}\right) .
$$

We then minimize the sum of squared deviations from the implied volatility in the data,

$$
\min _{\theta} \sum_{j=1}^{n}\left(\sigma_{j, t}(\theta)-\sigma_{j, t}\right)^{2} .
$$

As Christoffersen and Jacobs note, this is just a weighted least squares problem that, with the monotonicity of the option price in $\theta$, satisfies the usual regularity conditions.

We next fit (25) to daily option prices for the FF and BP in intervals around the two crises. We first estimate the probability of a depreciation of at least $3 \%$ in a four-week horizon. We chose the jump size to be large enough for the BP to escape from the midpoint of the upper half of the band. We defer discussion of the entire predictive density until Section 5 after we develop forecasts using both options and spot market models.

\subsubsection{French Franc Options Estimates}

We estimate the six parameter model day-by-day from January 1 to August 5, 1993 for the FF. We report coefficient estimates, $t$-ratios, and $R^{2}$ in Table 1 for the crisis period, July 16 to August 5,1993 . The model describes the option prices well with an average goodness of fit of $97 \%$.

\section{[INSERT Table 1]}

From the fitted model, we back out an implied distribution for the spot exchange rate returns over a four week interval. We plot in Figure 4 the 3\% devaluation risk for January-August 1993. 


\section{[INSERT Figure 4]}

We also compute an empirical 95\% confidence intervals based on the sampling distribution of the devaluation risk. A risk above $21.15 \%$ is in the upper $5 \%$ tail. All of the highest risk occur in the period immediately before and after the crisis. The one exception is the $22.57 \%$ spike on January 11, 1993 that quickly diminished.

In the period leading up to the crisis, the devaluation risk, depicted in Figure 5, starts at less than $1 \%$ on July 18, quickly rises to nearly $23 \%$ on July 20 and peaks at nearly $25 \%$ on July 26 . The risk stays above $20 \%$ for 6 of the 7 days prior to the FF's de facto devaluation.

\section{[INSERT Figure 5]}

This exercise, we feel, is largely successful. The model fits the data well and provides a sharp increase in devaluation risk 11 days before the FF bands widen. In principal, this could provide sufficient time for the central bank to react to market expectations.

\subsubsection{British Pound Options Estimates}

We next estimate the model for January 1 to September 29, 1992 for the BP. We report coefficient estimates, $t$-ratios, and $R^{2}$ in Table 2 for the crisis period August 19 to September 29, 1992. The model again captures the data well with an average $R^{2}$ of $96 \%$.

\section{[INSERT Table 2]}

The option implied devaluation risk is consistently under $20 \%$ and below the upper $5 \%$ risk level of $20.97 \%$ for all but 3 days prior to the crisis. On January 16, 17 and 24, 1992, the devaluation risk in Figure 6 rises above $21 \%$.

\section{[INSERT Figure 6]}

At the beginning of the crisis period displayed in Figure 7, the devaluation risk on August 19, 1992 is below the sample average of $16.20 \%$. It rises steadily into the crisis, except for two steep declines on September 4 and September 11, 1992. The risk exceeds $20 \%$ for 17 out of 18 trading days prior to the BP devaluation on September 17, 1992.

\section{[INSERT Figure 7]}

The options again provide a potential early warning signal to policy makers. The devaluation risk exceeds the 5\% limit on August 20, 1992, 25 days before the British Pound leaves the ERM.

We now turn to the spot market volatility to search for possible signals of the crises. 


\subsection{The Spot Market}

\subsubsection{French Franc}

As we do not model the dynamics of the interest rates, and are interested in one-month-ahead density forecasts, we estimate the LMARX-GARCH model with monthly data. For the FF, we use monthly percentage returns, $r_{t}=100 \times \log \left(S_{t} / S_{t-1}\right)$, from May 1979 to December 31, 1992, a total of 172 monthly observations. Maximum likelihood estimates ${ }^{9}$ of the model described in Section 3.2.1 are reported in Table 3.

As expected, $\gamma_{1}>0$ and $\phi_{1}<0$, so that both the probability of a jump, $\lambda_{t}$, as well as the expected jump size, $\mu_{1, t}$, increase when the yield curve inverts. Also, $\psi_{1}<0$, that is, there is mean reversion when the target zone is credible.

From the fitted model, we compute the four-week-ahead densities for the period from July 16 to August 5, 1993. The implied densities of the percentage log-change of the FF against the DM four weeks from the trading date are summarized in Table 4.

[Insert Table 4]

To illustrate the flexibility of the density forecasts resulting from the LMARX-GARCH model, The top panel of Figure 8 shows the predictive densities calculated for July 21 and July 30, respectively. While the density forecast of July 21 is somewhat skewed to the right, the predictive density for July 30, shortly before the de facto devaluation of the Franc, exhibits a pronounced bimodality. Figure 8 also shows the probability weighted mixture components, i.e., $\lambda_{t} \phi\left(r_{t} ; \mu_{1, t}, \sigma_{1, t}^{2}\right)$ and $\left(1-\lambda_{t}\right) \phi\left(r_{t} ; \mu_{2, t}, \sigma_{2, t}^{2}\right)$, in the middle panel, as well as the raw densities, $\phi\left(r_{t} ; \mu_{1, t}, \sigma_{1, t}^{2}\right)$ and $\phi\left(r_{t} ; \mu_{2, t}, \sigma_{2, t}^{2}\right)$, in the bottom panel. The weighted densities document the contribution of each component to the overall mixture density. Hence, the middle panel illustrates the increasing importance of the first component a few days before the crisis. From the bottom panel, we note that the probability mass of the second (credibility) density is essentially concentrated between -2 and 2, as implied by the exchange rate mechanism.

\section{[INSERT Figure 8]}

The normal mixture densities extracted from the time series of currency prices demonstrate a considerable increase in downside risk at least a week before the de facto devaluation of the Franc,

${ }^{9}$ See Haas, Mittnik and Paolella (2004a) for a discussion of maximum likelihood estimation. See also Alexander and Lazar (2004) for the special GARCH(1,1)-mixture case. 
with a further sharp increase immediately before the widening of the target zone, that is, on July 30. The evolution of the probabilities is shown in Figures 9 and 10.

[INSERT Figure 9]

[INSERT Figure 10]

\subsubsection{British Pound}

Given the short period of time of the BP belonging to the EMS, we do not necessarily expect to fit a meaningful model as we did for the FF. This is already evident from the right panel of Figure 1 , where the relation between the yield curve and the next period's return is shown for the BP. Obviously, there is much less information in the British yield curve than is in the French. This, of course, was expected due to the well-known differences between exchange rates in the EMS and floating systems (Neely, 1994).

We make use of pre-ERM data, that is, we use monthly returns from January 1978 to December 31, 1991 (176 observations), to fit the MN-GARCH model discussed in Section 3.2.2. The parameter estimates for this model are reported in Table 5. The implied densities of the percentage log-change of the BP against the DM four weeks from the trading date, for the period August 19 to September 29, 1992 are summarized in Table 6.

\section{[Insert Table 5]}

[Insert Table 6]

The conditional four-week-ahead densities for a pre- and a post-crisis day are shown in Figure 11. The mixture components are both centered around zero, only their variances differ, so there is a considerable overlap. This is in contrast to the results for the Franc, where the components are very well separated, because their means are far enough apart, relative to the variances. The mixture for the Pound, thus, mainly captures the kurtosis in the data, but incorporates no information about regime-specific conditional means.

\section{[INSERT Figure 11]}

The model's probabilities of a devaluation of at least 3\% are shown in Figures 12 and 13, with Figure 12 displaying empirical 95\% confidence limits.

[INSERT Figure 12]

[INSERT Figure 13]

As was expected in view of the right panel of Figure 1, the parameter estimates in Table 5 do 
not represent meaningful economic relationships. The positive $\gamma_{1}$ implies that the weight of the first component increases when the yield curve inverts, but its mean, $\mu_{1, t}$, decreases. This means that the probability of a devaluation decreases when the yield curve inverts, and gives rise to the very strange result that the probability of a large devaluation initially decreases on September 17, 1992 when the Pound left the EMS and the yield curve is negative with $y c_{t}=i_{t}^{3}-i_{t}^{1}=-2.5$. Subsequently, the probability increases only as a result of the GARCH effects in the component variances. Clearly the numbers describing the conditional mean dynamics cannot be given any interpretation, due to their very large (approximate) standard errors. However, the MN-GARCH structure is reasonable for the data, given that the jump size $\delta^{2}$ is rather large, implying a considerable difference between the component variances.

Summarizing the results for the Pound, we conclude that lacking characteristic information in the sample used for estimation, the mixed normal GARCH model does not anticipate the withdrawal of the pound from the EMS, and so, the probability of a large devaluation rises only ex-post, due to the GARCH effects in the mixture model.

\section{Comparison of Predictive Densities}

Next, we evaluate the forecast densities produced by our two models. The approach we take is the one originally proposed by Berkowitz (2001). Let $f\left(s_{t}\right)$ be the probability density of the spot exchange rate, and let $F\left(s_{t}\right)$ be the cumulative distribution

$$
F\left(s_{t}\right)=\int_{-\infty}^{s_{t}} f(u) d u
$$

Berkowitz notes that estimates $\widehat{F}\left(s_{t}\right)$ are uniform, independent and identically distributed under fairly weak assumptions.

Testing for an independent uniform density in small samples can be problematic, so Berkowitz suggests transforming the data into normal random variates,

$$
z_{t}=\Phi^{-1}\left(\widehat{F}\left(s_{t}\right)\right)
$$

where $\Phi(\cdot)$ denotes again the standard normal distribution. ${ }^{10}$ The likelihood ratio,

$$
L R=\sum_{t=1}^{20}\left(\frac{z_{t}^{2}}{\hat{\sigma}^{2}}-1\right)
$$

where $\hat{\sigma}$ is the forecast standard deviation, is then approximately distributed $\chi^{2}(1)$ for the null

$\overline{10}$ We use the numerical transformation for the inverse normal proposed by Wichura (1988). 
hypothesis that the transformed forecast statistics, $z_{t}$, have mean zero.

\subsection{Option forecasts}

We test the forecast densities for the FF from July 20 to August 29, 1993. Likelihood-ratio statistics are in the last column of Table 1 . At the $10 \%$ level, we can accept the null that our forecast could have generated the subsequent four weeks of trading data from July 21 through the rest of the crisis. After that point, our model is statistically indistinguishable from the post-crisis density except for two days in August.

We do the same exercise for the BP for the period August 20 to September 29, 1992. There are stronger rejections prior to this crisis. Nonetheless, on August 20, 21 and September 1 and 2, we have a forecast consistent with the four-week returns data at the $10 \%$ level.

\subsection{Spot market forecasts}

Ignoring non-trading days, as we do in model specification and estimation, the 20-trading dayahead forecast density is given by a mixture of two normals, namely,

$$
f\left(r_{t+20} \mid \Psi_{t}\right)=\sum_{j=1}^{2} \lambda_{j, t+20} \frac{1}{\sqrt{2 \pi} \sigma_{j, t+20}} e^{\left\{-\frac{\left(r_{t+20}-\mu_{j, t+20}\right)^{2}}{2 \sigma_{j, t+20}^{2}}\right\}},
$$

where $r_{t+20}=100 \times\left(\log S_{t+20}-\log S_{t}\right)$. Under constancy assumptions, we can scale the 20-day ahead densities to obtain daily $\log$-changes $r_{t+\tau}^{d}:=100 \times\left(\log S_{t+\tau}-\log S_{t+\tau-1}\right), \tau=1, \ldots, 20$, implying a two-component normal mixture distribution, given by

$$
f\left(r_{t+\tau}^{d} \mid \Psi_{t}\right)=\sum_{j=1}^{2} \lambda_{j, t+20} \frac{1}{\sqrt{2 \pi} \sigma_{j, t+20} / \sqrt{20}} e^{\left\{-\frac{\left(r_{t+\tau}^{d}-\mu_{j, t+20} / 20\right)^{2}}{2 \sigma_{j, t+20}^{2} / 20}\right\}} .
$$

Expression (28) can be used to compute the cumulative distribution function $F\left(r_{t+\tau}^{d} \mid \Psi_{t}\right)$ and transformation $z_{t}=\Phi^{-1}\left(F\left(r_{t+\tau}^{d} \mid \Psi_{t}\right)\right), \tau=1, \ldots, 20$. Then, provided our density predictions are correctly specified, the likelihood ratio (26) again has an approximate $\chi^{2}(1)$ distribution. Using (26), we test for a correct specification of the mean of our forecast distribution. In principle, we could test for additional properties of the forecast density, such as skewness - reflecting in our mixture models some sense of the realignment risk - or kurtosis. However, with only 20 data points at hand, any test involving higher-order forecast moments is rather questionable.

The test results are reported in Tables 4 and 6 for the FF and BP, respectively. For the latter, the parameters of the 20-day-ahead forecast densities are not reported, given that they are all constant with the exception of $\sigma_{2, t}^{2}$. In terms of the LR test (26), the dynamic mixture model 
performs well for the FF, but, as expected, exhibits a poor performance in predicting the crisis of the BP.

\section{Conclusion}

Analyzed with some recently developed modeling techniques, asset prices can provide insights into the entire probability distribution of future events. This paper has utilized the mixture of $\log$ normals in two separate contexts: with options and with the underlying currencies.

The crisis of the European Exchange Rate Mechanism case was certainly an epochal event for the markets, where central bankers became aware - perhaps for the first time - that the markets might be an irresistible force.

Policy makers may find these tools and inference worthwhile in a variety of contexts. Their subjective weights between type I and type II errors should not only be tested ex-post but incorporated directly in the estimation. Both Skouras (2001) and Christoffersen and Jacobs (2001) have made progress along these lines. Loss aversion on the part of investors and traders may give them similar preferences.

Whether or not the accuracy of density predictions can be improved by combining options and spot-market information is the subject of future research. One possible strategy in this direction, employed in Claessen and Mittnik (2002), is to use implied volatility as an explanatory variable in the GARCH equation. Alternatively, the predicted density could be formed by a mixture of options- and the spot market-based density predictions. 


\section{References}

Alexander, C. and E. Lazar (2004), "Normal Mixture GARCH(1,1). Applications to Exchange Rate Modelling," ISMA Centre Discussion Papers in Finance 2004-06, The Business School for Financial Markets at the University of Reading.

Bakshi, C., Cao, C. and Z. Chen (1997), "Empirical Performance of Alternative Option Pricing Models," Journal of Finance 52, 2003-2049.

Barone-Adesi, G. and R.E. Whaley, (1987), "Efficient Analytic Approximation of American Option Values," Journal of Finance 42, 301-20.

Bates, D. (1991), "The Crash of '87: Was it Expected? The Evidence from Options Markets," Journal of Finance 46, 1009-44.

Beine, M. and S. Laurent (2003), "Central Bank Interventions and Jumps in Double Long Memory Models of Daily Exchange Rates," Journal of Empirical Finance 10, 641-660.

Beine, M., Laurent, S., and C. Lecourt, (2003), "Official Central Bank Interventions and Exchange Rate Volatility: Evidence from a Regime-Switching Analysis," European Economic Review 47, 891-911.

Bekaert, G. and S. F. Gray, (1998), "Target Zones and Exchange Rates: An Empirical Investigation," Journal of International Economics 45, 1-35.

Berkowitz, J. (2001), "Testing Density Forecasts with Applications to Risk Management," Journal of Business and Economic Statistics 19, 466-74.

Bjerksund, P. and G. Stensland, (1993), "Closed-Form Approximation of American Options," Scandinavian Journal of Management 9, 87-99.

Robert R. Bliss, R. and N. Panigirtzoglou, (2002), "Testing the Stability of Implied Probability Density Functions," Journal of Banking and Finance 26, 381-422

Breeden, D. and R. Litzenberger (1978), "State Contingent Prices Implicit in Option Prices," Journal of Business 51, 621-51.

Bollerslev, T, (1986), "Generalized Autoregressive Conditional Heteroskedasticity," Journal of Econometrics 31, 307-327.

Campa, J. and P.H.K. Chang (1996), "Arbitrage Based Tests of Target Zone Credibility: Evidence from ERM Cross Rate Options," American Economic Review 86, 726-40.

Christoffersen, P. and K. Jacobs (2001), "The Importance of the Loss Function in Option Pricing," CIRANO Working Paper 2001-45.

Christoffersen, P. and S. Mazzotta (2004), "The Informational Content of Over the Counter Currency Options," CIRANO Working Paper 2004-16.

Claessen, H. and S. Mittnik (2002), Forecasting Stock Market Volatility and the Informational Efficiency of the DAX-Index Options Market, European Journal of Finance 8, 302-321.

Das, S.R. and R.K. Sundaram, (1999), "Of Smiles and Smirks: A Term-Structure Perspective," Journal of Financial and Quantitative Analysis 34, 211-239. 
Dumas, B., J. Fleming, and R. Whaley, (1998), "Implied Volatility Functions: Empirical Tests," Journal of Finance 53, 2059-2106.

Dupire, B. (1994), "Pricing with a Smile," Risk 7, 18-20.

Engel, C. and Hakkio, C. S., (1996), "The Distribution of Exchange Rates in the EMS," International Journal of Finance and Economics 1, 55-67.

Haas, M., Mittnik, S., and M. S. Paolella, (2004a), "Mixed Normal Conditional Heteroskedasticity." Journal of Financial Econometrics 2, 211-250.

Haas, M., Mittnik, S., and M. S. Paolella, (2004b), "A New Approach to Markov-Switching GARCH Models," Journal of Financial Econometrics 2, 493-530.

Heston, S. (1993), "A Closed Form Solution for Options with Stochastic Volatility with Applications to Bond and Currency Options," Review of Financial Studies 6, 327-43.

Hoffman, C. (2000), "Valuation of American Options," Oxford University Thesis.

Hull, J. and A. White (1987), "The Pricing of Options on Assets with Stochastic Volatility," Journal of Finance, 42, 281-300.

Klaster, M. A. and K. H. W. Knot, (2002), "Toward an Econometric Target Zone Model with Endogenous Devaluation Risk for a Small Open Economy, "Economic Modelling 19, 509-529.

Lanne, M. and P. Saikkonen, (2003), "Modeling the U.S. Short-Term Interest Rate by Mixture Autoregressive Processes," Journal of Financial Econometrics 1, 96-125.

Malz, A. (1996) "Using Option Prices to Estimate Realignment Probabilities in the European Monetary System," Journal of International Money and Finance 15, 717-48.

Melick, W. and C. Thomas (1997), "Recovering an Asset's Implied PDF from Option Prices: An Application to Crude Oil During the Gulf Crisis," Journal of Financial and Quantitative Analysis $32,91-115$.

Merton, R. (1976), "Option Pricing when Underlying Stock returns are Discontinuous," Journal of Financial Economics, 3, 124-44.

Mizrach, B., (1995), "Target Zone Models with Stochastic Realignments: An Econometric Evaluation." Journal of International Money and Finance 14, 641-657.

Mizrach, B. (2002), "When Did the Smart Money in Enron Lose Its' Smirk?," Rutgers University Working Paper \#2002-24.

Neely, C. J., (1994), "Realignments of Target Zone Exchange Rate Systems: What Do We Know?" Federal Reserve Bank of St. Louis Review 76, 23-34.

Neely, C. J., (1999), "Target Zones and Conditional Volatility: The Role of Realignment," Journal of Empirical Finance 6 177-192.

Palm, F. C. and P. J. G. Vlaar, (1997), "Simple Diagnostic Procedures for Modeling Financial Time Series," Allgemeines Statistisches Archiv 81, 85-101.

Ritchey, R, (1990), "Call Option Valuation for Discrete Normal Mixtures," Journal of Financial Research 13, 285-295. 
Shimko, D. (1993), "Bounds of Probability," Risk 6, 33-37.

Skouras, S. (2001), "Decisionmetrics: A Decision-Based Approach To Econometric Modelling, Santa Fe Institute Working Paper No. 01-10-64.

Stein, E.M. and J.C. Stein (1991), "Stock Price Distributions with Stochastic Volatility: An Analytic Approach," Review of Financial Studies 4, 727-52.

Vlaar, P. J. G. and F. C. Palm, (1993), "The Message in Weekly Exchange Rates in the European Monetary System: Mean Reversion, Conditional Heteroskedasticity, and Jumps, "Journal of Business and Economic Statistics 11, 351-360.

Wichura, M. J. (1988), "Algorithm AS 241: The Percentage Points of the Normal Distribution," Applied Statistics 37, 477-84.

Wiggins, J.B. (1987), "Option Values under Stochastic Volatility: Theory and Empirical Estimates," Journal of Financial Economics 19, 351-72.

Wong, C. S. and W. K. Li, (2001), "On a Logistic Mixture Autoregressive Model," Biometrika $88,833-846$. 
Table 1: French Franc Options Model

\begin{tabular}{|c|c|c|c|c|c|c|c|c|}
\hline Date & $\theta_{1}$ & $\theta_{2}$ & $\theta_{3}$ & $\theta_{4}$ & $\theta_{5}$ & $\theta_{6}$ & $R^{2}$ & $L R$ \\
\hline 16-Jul-1993 & $\begin{array}{c}-8.000 \\
(0.00)\end{array}$ & $\begin{array}{c}-5.346 \\
(0.04)\end{array}$ & $\begin{array}{c}3.766 \\
(0.00)\end{array}$ & $\begin{array}{c}-4.908 \\
(12.53)\end{array}$ & $\begin{array}{l}3.232 \\
(6.50)\end{array}$ & $\begin{array}{c}-7.740 \\
(0.00)\end{array}$ & 0.910 & \\
\hline 19-Jul-1993 & $\begin{array}{c}-0.174 \\
(0.00)\end{array}$ & $\begin{array}{c}1.928 \\
(0.80)\end{array}$ & $\begin{array}{c}-5.876 \\
(1.82)\end{array}$ & $\begin{array}{c}5.848 \\
(0.00)\end{array}$ & $\begin{array}{c}-2.269 \\
(1.27)\end{array}$ & $\begin{array}{c}-1.945 \\
(0.00)\end{array}$ & 0.990 & $\begin{array}{c}2.3752 \\
(0.12)\end{array}$ \\
\hline 20-Jul-1993 & $\begin{array}{c}-1.019 \\
(0.69) \\
\end{array}$ & $\begin{array}{l}-1.720 \\
(108.26)\end{array}$ & $\begin{array}{c}-0.191 \\
(1.79) \\
\end{array}$ & $\begin{array}{c}-3.441 \\
(0.00) \\
\end{array}$ & $\begin{array}{c}-4.006 \\
(0.00) \\
\end{array}$ & $\begin{array}{c}-4.233 \\
(0.00) \\
\end{array}$ & 0.990 & $\begin{array}{c}2.7213 \\
(0.10)\end{array}$ \\
\hline 21-Jul-1993 & $\begin{array}{c}-1.125 \\
(0.00)\end{array}$ & $\begin{array}{c}-1.042 \\
(0.01)\end{array}$ & $\begin{array}{c}-3.579 \\
(0.01)\end{array}$ & $\begin{array}{c}-0.474 \\
(0.00)\end{array}$ & $\begin{array}{c}-2.567 \\
(0.13)\end{array}$ & $\begin{array}{c}-2.056 \\
(0.05)\end{array}$ & 0.999 & $\begin{array}{c}1.1477 \\
(0.28)\end{array}$ \\
\hline 22-Jul-1993 & $\begin{array}{c}-1.505 \\
(0.02)\end{array}$ & $\begin{array}{c}-3.058 \\
(0.29)\end{array}$ & $\begin{array}{c}-4.188 \\
(0.00)\end{array}$ & $\begin{array}{c}-6.801 \\
(28.36)\end{array}$ & $\begin{array}{l}9.809 \\
(0.00)\end{array}$ & $\begin{array}{c}-2.147 \\
(0.00)\end{array}$ & 0.997 & $\begin{array}{c}1.7291 \\
(0.19)\end{array}$ \\
\hline 23-Jul-1993 & $\begin{array}{c}-2.504 \\
(0.03)\end{array}$ & $\begin{array}{c}-2.460 \\
(0.22)\end{array}$ & $\begin{array}{c}-0.325 \\
(0.00)\end{array}$ & $\begin{array}{c}-2.405 \\
(0.01)\end{array}$ & $\begin{array}{c}-1.034 \\
(0.01)\end{array}$ & $\begin{array}{c}-2.040 \\
(0.07)\end{array}$ & 0.993 & $\begin{array}{c}0.2145 \\
(0.64)\end{array}$ \\
\hline 26-Jul-1993 & $\begin{array}{c}-0.393 \\
(0.01) \\
\end{array}$ & $\begin{array}{c}-1.835 \\
(0.09) \\
\end{array}$ & $\begin{array}{c}-1.047 \\
(0.01) \\
\end{array}$ & $\begin{array}{c}-0.014 \\
(0.01) \\
\end{array}$ & $\begin{array}{c}-2.218 \\
(0.16) \\
\end{array}$ & $\begin{array}{c}-2.064 \\
(0.05) \\
\end{array}$ & 0.990 & $\begin{array}{c}1.1618 \\
(0.28)\end{array}$ \\
\hline 27-Jul-1993 & $\begin{array}{c}-3.945 \\
(0.06) \\
\end{array}$ & $\begin{array}{c}-2.111 \\
(36.96)\end{array}$ & $\begin{array}{c}17.480 \\
(0.00)\end{array}$ & $\begin{array}{c}-4.701 \\
(0.03) \\
\end{array}$ & $\begin{array}{c}-6.418 \\
(0.00)\end{array}$ & $\begin{array}{c}-4.795 \\
(0.00) \\
\end{array}$ & 0.994 & $\begin{array}{c}2.3117 \\
(0.14) \\
\end{array}$ \\
\hline 28-Jul-1993 & $\begin{array}{c}0.394 \\
(0.00) \\
\end{array}$ & $\begin{array}{c}-2.183 \\
(0.09) \\
\end{array}$ & $\begin{array}{c}-1.007 \\
(0.00) \\
\end{array}$ & $\begin{array}{c}-1.524 \\
(0.01) \\
\end{array}$ & $\begin{array}{c}-2.798 \\
(0.06) \\
\end{array}$ & $\begin{array}{c}-1.955 \\
(0.09) \\
\end{array}$ & 0.999 & $\begin{array}{c}2.1560 \\
(0.14) \\
\end{array}$ \\
\hline 29-Jul-1993 & $\begin{array}{c}-1.231 \\
(0.00) \\
\end{array}$ & $\begin{array}{c}-2.162 \\
(0.02) \\
\end{array}$ & $\begin{array}{c}-1.040 \\
(0.00)\end{array}$ & $\begin{array}{c}-0.328 \\
(0.00)\end{array}$ & $\begin{array}{c}-2.110 \\
(0.03) \\
\end{array}$ & $\begin{array}{c}-1.826 \\
(0.01) \\
\end{array}$ & 0.945 & $\begin{array}{c}0.6379 \\
(0.42)\end{array}$ \\
\hline 30-Jul-1993 & $\begin{array}{c}-1.355 \\
(0.01) \\
\end{array}$ & $\begin{array}{c}-1.637 \\
(0.05) \\
\end{array}$ & $\begin{array}{c}-1.490 \\
(0.01)\end{array}$ & $\begin{array}{c}-0.464 \\
(0.00) \\
\end{array}$ & $\begin{array}{c}-2.386 \\
(0.14) \\
\end{array}$ & $\begin{array}{c}-1.873 \\
(0.05) \\
\end{array}$ & 0.977 & $\begin{array}{c}1.1151 \\
(0.29)\end{array}$ \\
\hline 2-Aug-1993 & $\begin{array}{c}-1.029 \\
(0.01) \\
\end{array}$ & $\begin{array}{c}-0.035 \\
(0.01) \\
\end{array}$ & $\begin{array}{c}-4.371 \\
(0.73) \\
\end{array}$ & $\begin{array}{c}-0.324 \\
(0.00) \\
\end{array}$ & $\begin{array}{c}-2.139 \\
(0.73) \\
\end{array}$ & $\begin{array}{c}-2.222 \\
(1.20)\end{array}$ & 0.991 & $\begin{array}{c}3.2378 \\
(0.11) \\
\end{array}$ \\
\hline 3-Aug-1993 & $\begin{array}{c}3.192 \\
(0.23)\end{array}$ & $\begin{array}{c}-0.562 \\
(0.06)\end{array}$ & $\begin{array}{c}-3.473 \\
(0.21)\end{array}$ & $\begin{array}{c}-0.332 \\
(0.07)\end{array}$ & $\begin{array}{c}-3.207 \\
(1.52)\end{array}$ & $\begin{array}{c}-1.930 \\
(1.14)\end{array}$ & 0.986 & $\begin{array}{c}2.2335 \\
(0.14)\end{array}$ \\
\hline 4-Aug-1993 & $\begin{array}{c}-1.007 \\
(0.01) \\
\end{array}$ & $\begin{array}{c}-1.687 \\
(0.02) \\
\end{array}$ & $\begin{array}{c}-1.547 \\
(0.00) \\
\end{array}$ & $\begin{array}{c}-0.455 \\
(0.00)\end{array}$ & $\begin{array}{c}-2.472 \\
(0.07)\end{array}$ & $\begin{array}{c}-2.060 \\
(0.04)\end{array}$ & 0.912 & $\begin{array}{c}1.6081 \\
(0.20)\end{array}$ \\
\hline 5-Aug-1993 & $\begin{array}{c}0.083 \\
(0.01)\end{array}$ & $\begin{array}{c}-3.169 \\
(2.10)\end{array}$ & $\begin{array}{c}-0.776 \\
(0.20)\end{array}$ & $\begin{array}{c}-1.132 \\
(0.01)\end{array}$ & $\begin{array}{c}-1.880 \\
(0.06)\end{array}$ & $\begin{array}{c}-1.938 \\
(0.12)\end{array}$ & 0.974 & $\begin{array}{c}1.3703 \\
(0.24)\end{array}$ \\
\hline
\end{tabular}

The $\theta^{\prime} s$ are estimates of the model (25). $t$-ratios are in parentheses. The $L R$ statistic, with $p$-values underneath, is given by (26) and is distributed $\chi^{2}(1)$. 
Table 2: British Pound Options Model

\begin{tabular}{|c|c|c|c|c|c|c|c|c|}
\hline Date & $\theta_{1}$ & $\theta_{2}$ & $\theta_{3}$ & $\theta_{4}$ & $\theta_{5}$ & $\theta_{6}$ & $R^{2}$ & $L R$ \\
\hline 19-Aug-1992 & $\begin{array}{c}-30.857 \\
(0.00)\end{array}$ & $\begin{array}{c}-2.468 \\
(5.96) \\
\end{array}$ & $\begin{array}{l}6.351 \\
(0.02) \\
\end{array}$ & $\begin{array}{c}-5.617 \\
(5.51)\end{array}$ & $\begin{array}{l}1.879 \\
(1.84) \\
\end{array}$ & $\begin{array}{c}-1.982 \\
(0.00) \\
\end{array}$ & 0.995 & \\
\hline 20-Aug-1992 & $\begin{array}{c}-2.179 \\
(0.01)\end{array}$ & $\begin{array}{c}-1.908 \\
(0.15) \\
\end{array}$ & $\begin{array}{c}-0.816 \\
(0.01)\end{array}$ & $\begin{array}{c}-1.855 \\
(0.01) \\
\end{array}$ & $\begin{array}{c}-1.908 \\
(0.07) \\
\end{array}$ & $\begin{array}{c}-2.440 \\
(0.63) \\
\end{array}$ & 0.935 & $\begin{array}{c}1.5008 \\
(0.22)\end{array}$ \\
\hline 21-Aug-1992 & $\begin{array}{c}-1.620 \\
(0.01)\end{array}$ & $\begin{array}{c}-1.623 \\
(0.07)\end{array}$ & $\begin{array}{c}-2.679 \\
(0.02)\end{array}$ & $\begin{array}{c}-1.099 \\
(0.01)\end{array}$ & $\begin{array}{c}-1.859 \\
(0.14)\end{array}$ & $\begin{array}{c}-2.435 \\
(0.90)\end{array}$ & 0.973 & $\begin{array}{c}2.4618 \\
(0.12)\end{array}$ \\
\hline 24-Aug-1992 & $\begin{array}{c}-2.374 \\
(0.26)\end{array}$ & $\begin{array}{c}-2.609 \\
(4.98)\end{array}$ & $\begin{array}{c}-0.452 \\
(0.27)\end{array}$ & $\begin{array}{l}-1.805 \\
(0.08)\end{array}$ & $\begin{array}{c}-1.409 \\
(0.37)\end{array}$ & $\begin{array}{c}-1.897 \\
(1.01)\end{array}$ & 0.967 & $\begin{array}{c}3.5960 \\
(0.06)\end{array}$ \\
\hline 25-Aug-1992 & $\begin{array}{c}-17.296 \\
(0.00)\end{array}$ & $\begin{array}{c}-2.183 \\
(15.64)\end{array}$ & $\begin{array}{l}4.381 \\
(0.01)\end{array}$ & $\begin{array}{c}-4.843 \\
(2.67)\end{array}$ & $\begin{array}{l}0.987 \\
(0.63)\end{array}$ & $\begin{array}{c}-2.163 \\
(0.00)\end{array}$ & 0.974 & $\begin{array}{c}7.8066 \\
(0.01)\end{array}$ \\
\hline 26-Aug-1992 & $\begin{array}{c}-2.306 \\
(0.12) \\
\end{array}$ & $\begin{array}{c}-2.614 \\
(1.10) \\
\end{array}$ & $\begin{array}{c}-0.467 \\
(0.05) \\
\end{array}$ & $\begin{array}{c}-2.018 \\
(0.05) \\
\end{array}$ & $\begin{array}{c}-1.595 \\
(0.30) \\
\end{array}$ & $\begin{array}{c}-1.865 \\
(0.60) \\
\end{array}$ & 0.988 & $\begin{array}{c}6.5960 \\
(0.01)\end{array}$ \\
\hline 27-Aug-1992 & $\begin{array}{c}-2.601 \\
(0.05)\end{array}$ & $\begin{array}{c}-2.465 \\
(0.57)\end{array}$ & $\begin{array}{c}-0.479 \\
(0.02)\end{array}$ & $\begin{array}{c}-1.722 \\
(0.02)\end{array}$ & $\begin{array}{c}-1.706 \\
(0.26)\end{array}$ & $\begin{array}{c}-1.934 \\
(0.29)\end{array}$ & 0.990 & $\begin{array}{c}6.8458 \\
(0.04)\end{array}$ \\
\hline 31-Aug-1992 & $\begin{array}{c}-2.314 \\
(0.00)\end{array}$ & $\begin{array}{c}14.497 \\
(0.00)\end{array}$ & $\begin{array}{c}-7.251 \\
(11.92) \\
\end{array}$ & $\begin{array}{c}-4.856 \\
(0.27) \\
\end{array}$ & $\begin{array}{c}-3.710 \\
(0.04)\end{array}$ & $\begin{array}{c}-2.204 \\
(0.00)\end{array}$ & 0.908 & $\begin{array}{c}4.6372 \\
(0.03)\end{array}$ \\
\hline 1-Sep-1992 & $\begin{array}{c}-2.165 \\
(0.05)\end{array}$ & $\begin{array}{c}2.541 \\
(0.45)\end{array}$ & $\begin{array}{c}-0.595 \\
(0.01)\end{array}$ & $\begin{array}{c}-1.656 \\
(0.01)\end{array}$ & $\begin{array}{c}1.567 \\
(0.06)\end{array}$ & $\begin{array}{c}-1.992 \\
(0.09)\end{array}$ & 0.948 & $\begin{array}{c}2.6884 \\
(0.10)\end{array}$ \\
\hline 2-Sep-1992 & $\begin{array}{c}-2.541 \\
(0.13) \\
\end{array}$ & $\begin{array}{c}-2.194 \\
(0.95) \\
\end{array}$ & $\begin{array}{c}0.930 \\
(0.01)\end{array}$ & $\begin{array}{c}-5.933 \\
(2.28) \\
\end{array}$ & $\begin{array}{l}1.135 \\
(0.64)\end{array}$ & $\begin{array}{c}-2.000 \\
(0.52) \\
\end{array}$ & 0.974 & $\begin{array}{c}2.6996 \\
(0.10)\end{array}$ \\
\hline 3-Sep-1992 & $\begin{array}{c}-4.724 \\
(0.02)\end{array}$ & $\begin{array}{c}-2.178 \\
(0.59)\end{array}$ & $\begin{array}{c}-0.205 \\
(0.16)\end{array}$ & $\begin{array}{c}-3.812 \\
(0.18)\end{array}$ & $\begin{array}{c}-0.685 \\
(0.07)\end{array}$ & $\begin{array}{c}-2.077 \\
(0.55)\end{array}$ & 0.945 & $\begin{array}{c}4.1894 \\
(0.04)\end{array}$ \\
\hline 4-Sep-1992 & $\begin{array}{c}2.824 \\
(0.66)\end{array}$ & $\begin{array}{c}-0.324 \\
(0.27)\end{array}$ & $\begin{array}{c}-3.620 \\
(1.15)\end{array}$ & $\begin{array}{l}0.390 \\
(0.09)\end{array}$ & $\begin{array}{c}-2.823 \\
(1.88)\end{array}$ & $\begin{array}{c}-1.757 \\
(1.28)\end{array}$ & 0.990 & $\begin{array}{c}3.3074 \\
(0.07)\end{array}$ \\
\hline 8-Sep-1992 & $\begin{array}{c}-3.384 \\
(0.13)\end{array}$ & $\begin{array}{c}-2.216 \\
(1.40)\end{array}$ & $\begin{array}{c}0.734 \\
(0.01)\end{array}$ & $\begin{array}{l}-4.205 \\
(1.85)\end{array}$ & $\begin{array}{c}-0.028 \\
(0.02)\end{array}$ & $\begin{array}{c}-2.040 \\
(0.51)\end{array}$ & 0.992 & $\begin{array}{c}5.4434 \\
(0.02)\end{array}$ \\
\hline 9-Sep-1992 & $\begin{array}{c}-0.651 \\
(0.01) \\
\end{array}$ & $\begin{array}{c}43.422 \\
(0.00) \\
\end{array}$ & $\begin{array}{c}-8.564 \\
(16.27) \\
\end{array}$ & $\begin{array}{c}-2.607 \\
(6.56)\end{array}$ & $\begin{array}{c}-10.131 \\
(0.00)\end{array}$ & $\begin{array}{c}-1.936 \\
(0.00)\end{array}$ & 0.960 & $\begin{array}{c}4.9878 \\
(0.03)\end{array}$ \\
\hline 10-Sep-1992 & $\begin{array}{c}-2.968 \\
(0.02)\end{array}$ & $\begin{array}{c}-0.836 \\
(0.13)\end{array}$ & $\begin{array}{c}-2.859 \\
(0.17)\end{array}$ & $\begin{array}{l}0.017 \\
(0.11)\end{array}$ & $\begin{array}{c}-2.226 \\
(0.94)\end{array}$ & $\begin{array}{c}-2.019 \\
(0.50)\end{array}$ & 0.990 & $\begin{array}{c}3.4620 \\
(0.06)\end{array}$ \\
\hline 11-Sep-1992 & $\begin{array}{c}-2.259 \\
(0.06)\end{array}$ & $\begin{array}{c}-3.154 \\
(1.22)\end{array}$ & $\begin{array}{c}-0.597 \\
(0.52)\end{array}$ & $\begin{array}{c}-1.889 \\
(0.79)\end{array}$ & $\begin{array}{c}-0.879 \\
(1.43)\end{array}$ & $\begin{array}{c}-1.891 \\
(3.37) \\
\end{array}$ & 0.965 & $\begin{array}{c}3.9484 \\
(0.05)\end{array}$ \\
\hline 14-Sep-1992 & $\begin{array}{c}-1.592 \\
(0.06)\end{array}$ & $\begin{array}{c}-2.197 \\
(0.84)\end{array}$ & $\begin{array}{c}-0.517 \\
(0.01)\end{array}$ & $\begin{array}{c}-3.083 \\
(0.16)\end{array}$ & $\begin{array}{c}-0.737 \\
(0.09)\end{array}$ & $\begin{array}{c}-2.011 \\
(0.55)\end{array}$ & 0.978 & $\begin{array}{c}2.9796 \\
(0.08)\end{array}$ \\
\hline 15-Sep-1992 & $\begin{array}{c}-3.353 \\
(0.01) \\
\end{array}$ & $\begin{array}{c}-1.991 \\
(0.17) \\
\end{array}$ & $\begin{array}{c}-1.054 \\
(0.01) \\
\end{array}$ & $\begin{array}{c}-1.719 \\
(0.01) \\
\end{array}$ & $\begin{array}{c}-1.801 \\
(0.09) \\
\end{array}$ & $\begin{array}{c}-1.898 \\
(0.21) \\
\end{array}$ & 0.980 & $\begin{array}{c}1.7626 \\
(0.18)\end{array}$ \\
\hline 16-Sep-1992 & $\begin{array}{c}-128.074 \\
(0.00)\end{array}$ & $\begin{array}{c}-2.008 \\
(40.88)\end{array}$ & $\begin{array}{c}16.878 \\
(0.00)\end{array}$ & $\begin{array}{c}-5.017 \\
(53.64)\end{array}$ & $\begin{array}{c}5.456 \\
(0.00)\end{array}$ & $\begin{array}{c}-3.079 \\
(0.00)\end{array}$ & 0.980 & $\begin{array}{c}0.8910 \\
(0.35)\end{array}$ \\
\hline 17-Sep-1992 & $\begin{array}{c}-0.882 \\
(0.07)\end{array}$ & $\begin{array}{c}-0.943 \\
(0.48)\end{array}$ & $\begin{array}{c}-3.634 \\
(0.48)\end{array}$ & $\begin{array}{c}-3.108 \\
(0.02)\end{array}$ & $\begin{array}{c}-2.051 \\
(0.09)\end{array}$ & $\begin{array}{c}-1.933 \\
(2.12)\end{array}$ & 0.985 & $\begin{array}{c}0.7756 \\
(0.38)\end{array}$ \\
\hline 18-Sep-1992 & $\begin{array}{c}-5.051 \\
(0.05)\end{array}$ & $\begin{array}{c}-2.165 \\
(0.49)\end{array}$ & $\begin{array}{c}-0.453 \\
(0.01)\end{array}$ & $\begin{array}{c}-3.130 \\
(0.17)\end{array}$ & $\begin{array}{c}-0.889 \\
(0.19)\end{array}$ & $\begin{array}{c}-1.735 \\
(0.49)\end{array}$ & 0.928 & $\begin{array}{c}0.8970 \\
(0.34)\end{array}$ \\
\hline 21-Sep-1992 & $\begin{array}{c}-4.066 \\
(0.01)\end{array}$ & $\begin{array}{c}-2.235 \\
(0.43)\end{array}$ & $\begin{array}{c}-0.436 \\
(0.03)\end{array}$ & $\begin{array}{c}-1.379 \\
(0.08)\end{array}$ & $\begin{array}{c}-2.102 \\
(0.13)\end{array}$ & $\begin{array}{c}-1.601 \\
(1.48) \\
\end{array}$ & 0.908 & $\begin{array}{c}0.8004 \\
(0.37)\end{array}$ \\
\hline 22-Sep-1992 & $\begin{array}{c}-6.819 \\
(0.00) \\
\end{array}$ & $\begin{array}{c}-2.284 \\
(1.50) \\
\end{array}$ & $\begin{array}{c}-0.241 \\
(0.07) \\
\end{array}$ & $\begin{array}{c}-2.746 \\
(0.15) \\
\end{array}$ & $\begin{array}{c}-0.900 \\
(0.16) \\
\end{array}$ & $\begin{array}{c}-1.886 \\
(0.68) \\
\end{array}$ & 0.975 & $\begin{array}{c}0.4570 \\
(0.50)\end{array}$ \\
\hline 23-Sep-1992 & $\begin{array}{c}-1.142 \\
(0.00)\end{array}$ & $\begin{array}{c}-1.678 \\
(0.05)\end{array}$ & $\begin{array}{c}-4.145 \\
(0.01)\end{array}$ & $\begin{array}{c}-6.490 \\
(4.69)\end{array}$ & $\begin{array}{l}3.387 \\
(0.01)\end{array}$ & $\begin{array}{c}-1.918 \\
(2.35)\end{array}$ & 0.987 & $\begin{array}{c}0.7244 \\
(0.39)\end{array}$ \\
\hline 24-Sep-1992 & $\begin{array}{c}2.741 \\
(0.05)\end{array}$ & $\begin{array}{c}-2.980 \\
(1.07)\end{array}$ & $\begin{array}{c}-0.844 \\
(0.18)\end{array}$ & $\begin{array}{l}-2.448 \\
(0.10)\end{array}$ & $\begin{array}{c}-0.977 \\
(0.14)\end{array}$ & $\begin{array}{c}-1.787 \\
(0.75)\end{array}$ & 0.955 & $\begin{array}{c}0.4260 \\
(0.51)\end{array}$ \\
\hline 25-Sep-1992 & $\begin{array}{c}-3.089 \\
(0.03)\end{array}$ & $\begin{array}{c}-2.012 \\
(0.38)\end{array}$ & $\begin{array}{c}0.772 \\
(0.00)\end{array}$ & $\begin{array}{c}-4.469 \\
(0.24)\end{array}$ & $\begin{array}{c}0.121 \\
(0.01)\end{array}$ & $\begin{array}{c}-1.956 \\
(0.17)\end{array}$ & 0.984 & $\begin{array}{c}0.7130 \\
(0.40)\end{array}$ \\
\hline 28-Sep-1992 & $\begin{array}{c}-2.325 \\
(0.04)\end{array}$ & $\begin{array}{c}-2.460 \\
(0.53)\end{array}$ & $\begin{array}{c}-0.781 \\
(0.04)\end{array}$ & $\begin{array}{c}-1.612 \\
(0.12)\end{array}$ & $\begin{array}{c}-1.536 \\
(0.30)\end{array}$ & $\begin{array}{c}-1.721 \\
(0.38)\end{array}$ & 0.970 & $\begin{array}{c}1.4356 \\
(0.23)\end{array}$ \\
\hline 29-Sep-1992 & $\begin{array}{c}-1.886 \\
(0.09)\end{array}$ & $\begin{array}{c}-0.884 \\
(0.39) \\
\end{array}$ & $\begin{array}{c}-2.202 \\
(0.29) \\
\end{array}$ & $\begin{array}{c}-0.640 \\
(0.15)\end{array}$ & $\begin{array}{c}-2.703 \\
(2.00) \\
\end{array}$ & $\begin{array}{c}-1.846 \\
(1.16) \\
\end{array}$ & 0.975 & $\begin{array}{c}2.3652 \\
(0.12)\end{array}$ \\
\hline
\end{tabular}

The $\theta^{\prime} s$ are estimates of the model (25). $t$-ratios are in parentheses. The $L R$ statistic, with $p$-values underneath, is given by (26) and is distributed $\chi^{2}(1)$. 


\section{Table 3: French Franc Spot Exchange Rate Model}

\begin{tabular}{|l|l|l|l|l|}
\hline$\sigma_{1}^{2}$ & $\alpha_{02}$ & $\alpha_{12}$ & $\beta_{22}$ & $\gamma_{0}$ \\
\hline \hline $\begin{array}{c}2.945 \\
(1.705)\end{array}$ & $\begin{array}{c}0.021 \\
(0.011)\end{array}$ & $\begin{array}{c}0.019 \\
(0.015)\end{array}$ & $\begin{array}{c}0.836 \\
(0.071)\end{array}$ & $\begin{array}{r}2.988 \\
(0.807)\end{array}$ \\
\hline \hline$\gamma_{1}$ & $\phi_{0}$ & $\phi_{1}$ & $\psi_{0}$ & $\psi_{1}$ \\
\hline \hline 1.711 & 2.048 & -1.049 & 0.093 & -2.820 \\
$(0.621)$ & $(1.297)$ & $(0.574)$ & $(0.036)$ & $(1.066)$ \\
\hline
\end{tabular}

Shown are the parameter estimates for the LMARX-GARCH for the French Franc (with approximate standard errors in parentheses), which is given by the following equations for the conditional density $f\left(r_{t} \mid \Psi_{t-1}\right)$ :

$$
\begin{aligned}
f\left(r_{t} \mid \Psi_{t-1}\right) & =\lambda_{t} \phi\left(r_{t} ; \mu_{1, t}, \sigma_{1, t}^{2}\right)+\left(1-\lambda_{t}\right) \phi\left(r_{t} ; \mu_{2, t}, \sigma_{2, t}^{2}\right), \\
r_{t} & =100 \times \log \left(S_{t} / S_{t-1}\right), \\
\phi\left(y ; \mu, \sigma^{2}\right) & =\frac{1}{\sigma \sqrt{2 \pi}} \exp \left\{-\frac{(y-\mu)^{2}}{2 \sigma^{2}}\right\}, \\
\lambda_{t} & =\left(1+\exp \left\{\gamma_{0}+\gamma_{1} y c_{t-1}^{\star}\right\}\right)^{-1}, \\
\mu_{1, t} & =\phi_{0}+\phi_{1} y c_{t-1}^{\star}, \\
\mu_{2, t} & =\psi_{0}+\psi_{1}\left(S_{t-1}-P_{t-1}\right), \\
\sigma_{2, t}^{2} & =\alpha_{02}+\alpha_{12} \epsilon_{t-1}^{2}+\beta_{22} \sigma_{2, t-1}^{2}, \\
\epsilon_{t} & =r_{t}-\lambda_{t} \mu_{1, t}-\left(1-\lambda_{t}\right) \mu_{2, t} .
\end{aligned}
$$

$S_{t}$ is the exchange rate at time $t, y c_{t}^{\star}=\operatorname{sign}\left(y c_{t}\right) \log \left(1+\left|y c_{t}\right|\right)$, where $y c_{t}$ is the slope of the French yield curve, i.e., the difference between the three-month and one-month interest rates, and $P_{t}$ is the central parity at time $t$. 
Table 4: French Franc Spot Exchange Rate Densities

\begin{tabular}{|c|c|c|c|c|c|c|c|c|}
\hline Date & $\lambda_{t}$ & $\mu_{1, t}$ & $\mu_{2, t}$ & $\sigma_{1, t}^{2}$ & $\sigma_{2, t}^{2}$ & $\bar{\mu}_{t}$ & $\bar{\sigma}_{t}^{2}$ & $L R$ \\
\hline 16-Jul-1993 & $\overline{0.073}$ & 2.323 & $\overline{-0.084}$ & 2.945 & 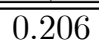 & 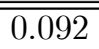 & 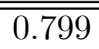 & \\
\hline 19-Jul-1993 & 0.074 & 2.331 & -0.068 & 2.945 & 0.186 & 0.109 & 0.785 & $\begin{array}{c}2.7435 \\
(0.10)\end{array}$ \\
\hline 20-Jul-1993 & 0.068 & 2.274 & -0.075 & 2.945 & 0.188 & 0.085 & 0.724 & $\begin{array}{c}1.7474 \\
(0.19)\end{array}$ \\
\hline 21-Jul-1993 & 0.048 & 2.048 & -0.085 & 2.945 & 0.190 & 0.017 & 0.530 & $\begin{array}{c}0.8250 \\
(0.36)\end{array}$ \\
\hline 22-Jul-1993 & 0.068 & 2.274 & -0.087 & 2.945 & 0.182 & 0.073 & 0.722 & $\begin{array}{c}0.3478 \\
(0.56)\end{array}$ \\
\hline 23-Jul-1993 & 0.232 & 3.147 & -0.087 & 2.945 & 0.178 & 0.664 & 2.686 & $\begin{array}{c}0.0003 \\
(0.99)\end{array}$ \\
\hline 26-Jul-1993 & 0.248 & 3.201 & -0.079 & 2.945 & 0.170 & 0.735 & 2.867 & $\begin{array}{c}0.0365 \\
(0.85)\end{array}$ \\
\hline 27-Jul-1993 & 0.248 & 3.201 & -0.078 & 2.945 & 0.170 & 0.736 & 2.865 & $\begin{array}{c}0.0185 \\
(0.89) \\
\end{array}$ \\
\hline 28-Jul-1993 & 0.182 & 2.958 & -0.064 & 2.945 & 0.164 & 0.485 & 2.028 & $\begin{array}{c}0.1819 \\
(0.67)\end{array}$ \\
\hline 29-Jul-1993 & 0.168 & 2.899 & -0.082 & 2.945 & 0.162 & 0.419 & 1.871 & $\begin{array}{c}0.1413 \\
(0.71) \\
\end{array}$ \\
\hline 30-Jul-1993 & 0.375 & 3.566 & -0.121 & 2.945 & 0.175 & 1.261 & 4.399 & $\begin{array}{c}0.0032 \\
(0.96) \\
\end{array}$ \\
\hline 02-Aug-1993 & 0.168 & 2.899 & -0.299 & 2.945 & 0.303 & 0.238 & 2.177 & $\begin{array}{c}0.0044 \\
(0.95)\end{array}$ \\
\hline 03-Aug-1993 & 0.209 & 3.062 & -0.318 & 2.945 & 0.334 & 0.387 & 2.767 & $\begin{array}{c}0.1947 \\
(0.66)\end{array}$ \\
\hline 04-Aug-1993 & 0.262 & 3.245 & -0.184 & 2.945 & 0.217 & 0.715 & 3.207 & $\begin{array}{c}0.0040 \\
(0.95)\end{array}$ \\
\hline 05-Aug-1993 & 0.242 & 3.179 & -0.222 & 2.945 & 0.226 & 0.601 & 3.006 & $\begin{array}{c}0.0175 \\
(0.89)\end{array}$ \\
\hline
\end{tabular}

Column 1 shows the day when the four-week-ahead forecast density is computed. Columns $2-6$ report the parameters of the predictive four-week-ahead normal mixture density for the respective trading days. Column 7 and 8 report the overall mean and variance, $\bar{\mu}_{t}:=E\left(r_{t} \mid \Psi_{t-1}\right)=\lambda_{t} \mu_{1, t}+\left(1-\lambda_{t}\right) \mu_{2, t}$ and $\bar{\sigma}_{t}^{2}:=\operatorname{Var}\left(r_{t} \mid \Psi_{t-1}\right)=\lambda_{t} \sigma_{1, t}^{2}+\left(1-\lambda_{t}\right) \sigma_{2, t}^{2}+\lambda_{t}\left(1-\lambda_{t}\right)\left(\mu_{1, t}-\mu_{2, t}\right)^{2}$. The last column shows the $L R$ statistic (26), with $p$-values underneath, which is distributed $\chi^{2}(1)$. 


\section{Table 5: British Pound Spot Exchange Rate Model}

\begin{tabular}{|l|l|l|l|l|}
\hline$\delta^{2}$ & $\alpha_{02}$ & $\alpha_{12}$ & $\beta_{22}$ & $\gamma_{0}$ \\
\hline \hline $\begin{array}{l}9.644 \\
(2.612)\end{array}$ & $\begin{array}{l}0.141 \\
(0.150)\end{array}$ & $\begin{array}{l}0.099 \\
(0.054)\end{array}$ & $\begin{array}{r}0.676 \\
(0.087)\end{array}$ & $\begin{array}{c}0.539 \\
(0.433)\end{array}$ \\
\hline \hline$\gamma_{1}$ & $\phi_{0}$ & $\phi_{1}$ & $\psi_{0}$ & $\psi_{1}$ \\
\hline \hline 0.896 & 0.960 & 2.776 & -0.153 & -0.048 \\
$(1.132)$ & $(0.626)$ & $(2.018)$ & $(0.190)$ & $(0.096)$ \\
\hline
\end{tabular}

Shown are the parameter estimates for the LMARX-GARCH model for the British Pound (with approximate standard errors in parentheses), which is given by the following equations for the conditional density $f\left(r_{t} \mid \Psi_{t-1}\right)$ :

$$
\begin{aligned}
f\left(r_{t} \mid \Psi_{t-1}\right) & =\lambda_{t} \phi\left(r_{t} ; \mu_{1, t}, \sigma_{1, t}^{2}\right)+\left(1-\lambda_{t}\right) \phi\left(r_{t} ; \mu_{2, t}, \sigma_{2, t}^{2}\right), \\
r_{t} & =100 \times \log \left(S_{t} / S_{t-1}\right), \\
\phi\left(y ; \mu, \sigma^{2}\right) & =\frac{1}{\sigma \sqrt{2 \pi}} \exp \left\{-\frac{(y-\mu)^{2}}{2 \sigma^{2}}\right\}, \\
\lambda_{t} & =\left(1+\exp \left\{\gamma_{0}+\gamma_{1} y c_{t-1}^{\star}\right\}\right)^{-1}, \\
\mu_{1, t} & =\phi_{0}+\phi_{1} y c_{t-1}^{\star}, \\
\mu_{2, t} & =\psi_{0}+\psi_{1} r_{t-1} \\
\sigma_{2, t}^{2} & =\alpha_{02}+\alpha_{12} \epsilon_{t-1}^{2}+\beta_{22} \sigma_{2, t-1}^{2}, \\
\sigma_{1, t}^{2} & =\sigma_{2, t}^{2}+\delta^{2} \\
\epsilon_{t} & =r_{t}-\lambda_{t} \mu_{1, t}-\left(1-\lambda_{t}\right) \mu_{2, t} .
\end{aligned}
$$

$S_{t}$ is the exchange rate at time $t$, and $y c_{t}^{\star}=\operatorname{sign}\left(y c_{t}\right) \log \left(1+\left|y c_{t}\right|\right)$, where $y c_{t}$ is the slope of the British yield curve, i.e., the difference between the three-month and one-month interest rates. 
Table 6: British Pound Spot Exchange Rate Densities

\begin{tabular}{|c|c|c|c|c|c|c|c|c|}
\hline Date & $\lambda_{t}$ & $\mu_{1, t}$ & $\mu_{2, t}$ & $\sigma_{1, t}^{2}$ & $\sigma_{2, t}^{2}$ & $\bar{\mu}_{t}$ & $\bar{\sigma}_{t}^{2}$ & $L R$ \\
\hline 19-Aug-1992 & 0.328 & 1.512 & $\overline{-0.191}$ & 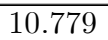 & 1.135 & 0.368 & 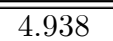 & \\
\hline 20-Aug-1992 & 0.323 & 1.580 & -0.208 & 10.785 & 1.141 & 0.370 & 4.957 & $\begin{array}{c}2.0796 \\
(0.15)\end{array}$ \\
\hline 21-Aug-1992 & 0.323 & 1.580 & -0.226 & 10.751 & 1.107 & 0.357 & 4.938 & $\begin{array}{c}3.1264 \\
(0.08)\end{array}$ \\
\hline 24-Aug-1992 & 0.323 & 1.580 & -0.231 & 10.691 & 1.046 & 0.355 & 4.881 & $\begin{array}{c}2.8652 \\
(0.09)\end{array}$ \\
\hline 25-Aug-1992 & 0.316 & 1.689 & -0.243 & 10.802 & 1.158 & 0.367 & 5.008 & $\begin{array}{c}1.7725 \\
(0.18)\end{array}$ \\
\hline 26-Aug-1992 & 0.328 & 1.512 & -0.234 & 10.674 & 1.030 & 0.339 & 4.866 & $\begin{array}{c}2.5806 \\
(0.11)\end{array}$ \\
\hline 27-Aug-1992 & 0.310 & 1.773 & -0.243 & 10.815 & 1.171 & 0.381 & 5.027 & $\begin{array}{c}2.6934 \\
(0.10)\end{array}$ \\
\hline 28-Aug-1992 & 0.292 & 2.030 & -0.245 & 10.909 & 1.265 & 0.420 & 5.154 & $\begin{array}{c}2.9932 \\
(0.08)\end{array}$ \\
\hline 1-Sep-1992 & 0.289 & 2.086 & -0.257 & 10.925 & 1.280 & 0.419 & 5.191 & $\begin{array}{c}2.2503 \\
(0.13)\end{array}$ \\
\hline 2-Sep-1992 & 0.270 & 2.367 & -0.238 & 10.820 & 1.176 & 0.467 & 5.121 & $\begin{array}{c}2.7256 \\
(0.10)\end{array}$ \\
\hline 3-Sep-1992 & 0.310 & 1.773 & -0.208 & 10.622 & 0.978 & 0.405 & 4.805 & $\begin{array}{c}4.2503 \\
(0.04)\end{array}$ \\
\hline 4-Sep-1992 & 0.340 & 1.348 & -0.198 & 10.462 & 0.818 & 0.328 & 4.631 & $\begin{array}{c}6.0795 \\
(0.01)\end{array}$ \\
\hline 7-Sep-1992 & 0.325 & 1.558 & -0.200 & 10.426 & 0.782 & 0.371 & 4.592 & $\begin{array}{c}7.3170 \\
(0.01)\end{array}$ \\
\hline 8-Sep-1992 & 0.328 & 1.512 & -0.221 & 10.494 & 0.850 & 0.348 & 4.676 & $\begin{array}{c}3.7090 \\
(0.05)\end{array}$ \\
\hline 9-Sep-1992 & 0.306 & 1.834 & -0.225 & 10.541 & 0.897 & 0.404 & 4.744 & $\begin{array}{c}3.0282 \\
(0.08)\end{array}$ \\
\hline 10-Sep-1992 & 0.319 & 1.646 & -0.215 & 10.591 & 0.947 & 0.378 & 4.771 & $\begin{array}{c}2.3305 \\
(0.13)\end{array}$ \\
\hline 11-Sep-1992 & 0.314 & 1.710 & -0.208 & 10.479 & 0.835 & 0.394 & 4.657 & $\begin{array}{c}1.5798 \\
(0.21)\end{array}$ \\
\hline 14-Sep-1992 & 0.362 & 1.043 & -0.161 & 10.487 & 0.843 & 0.275 & 4.672 & $\begin{array}{c}2.4595 \\
(0.12)\end{array}$ \\
\hline 15-Sep-1992 & 0.338 & 1.372 & -0.216 & 10.582 & 0.938 & 0.321 & 4.763 & $\begin{array}{c}1.4172 \\
(0.23)\end{array}$ \\
\hline 16-Sep-1992 & 0.405 & 0.478 & -0.214 & 10.612 & 0.967 & 0.066 & 4.992 & $\begin{array}{c}1.9766 \\
(0.16)\end{array}$ \\
\hline 17-Sep-1992 & 0.642 & -2.517 & -0.476 & 14.474 & 4.830 & -1.786 & 11.978 & $\begin{array}{c}2.6203 \\
(0.11)\end{array}$ \\
\hline 18-Sep-1992 & 0.465 & -0.274 & -0.507 & 15.322 & 5.678 & -0.399 & 10.175 & $\begin{array}{c}1.7021 \\
(0.19)\end{array}$ \\
\hline 21-Sep-1992 & 0.475 & -0.396 & -0.625 & 19.275 & 9.631 & -0.516 & 14.222 & $\begin{array}{c}1.3931 \\
(0.24)\end{array}$ \\
\hline 22-Sep-1992 & 0.456 & -0.165 & -0.615 & 18.857 & 9.212 & -0.410 & 13.662 & $\begin{array}{c}0.6636 \\
(0.42)\end{array}$ \\
\hline 23-Sep-1992 & 0.407 & 0.454 & -0.565 & 17.138 & 7.494 & -0.150 & 11.672 & $\begin{array}{c}1.2587 \\
(0.26)\end{array}$ \\
\hline 24-Sep-1992 & 0.411 & 0.409 & -0.618 & 18.959 & 9.315 & -0.196 & 13.531 & $\begin{array}{c}0.4803 \\
(0.49)\end{array}$ \\
\hline 25-Sep-1992 & 0.394 & 0.621 & -0.626 & 19.293 & 9.649 & -0.134 & 13.823 & $\begin{array}{c}0.2549 \\
(0.61)\end{array}$ \\
\hline 28-Sep-1992 & 0.413 & 0.386 & -0.653 & 20.359 & 10.715 & -0.225 & 14.955 & $\begin{array}{c}0.3857 \\
(0.53) \\
\end{array}$ \\
\hline 29-Sep-1992 & 0.396 & 0.597 & -0.625 & 19.244 & 9.600 & -0.141 & 13.777 & $\begin{array}{c}0.7949 \\
(0.37)\end{array}$ \\
\hline 30-Sep-1992 & 0.416 & 0.341 & -0.659 & 20.430 & 10.786 & -0.243 & 15.041 & $\begin{array}{c}0.3935 \\
(0.53)\end{array}$ \\
\hline
\end{tabular}

Column 1 shows the day when the four-week-ahead forecast density is computed. Columns 2-6 report the parameters of the predictive four-week-ahead normal mixture density. Column 7 and 8 report the overall mean and variance, $\bar{\mu}_{t}:=E\left(r_{t} \mid \Psi_{t-1}\right)=\lambda_{t} \mu_{1, t}+\left(1-\lambda_{t}\right) \mu_{2, t}$ and $\bar{\sigma}_{t}^{2}:=\operatorname{Var}\left(r_{t} \mid \Psi_{t-1}\right)=$ $\lambda_{t} \sigma_{1, t}^{2}+\left(1-\lambda_{t}\right) \sigma_{2, t}^{2}+\lambda_{t}\left(1-\lambda_{t}\right)\left(\mu_{1, t}-\mu_{2, t}\right)^{2}$. The last column shows the $L R$ statistic (26), with $p$-values underneath, which is distributed $\chi^{2}(1)$. 


\section{Figure 1: Scatter Plot Of Returns Against Slope Of Yield Curve}

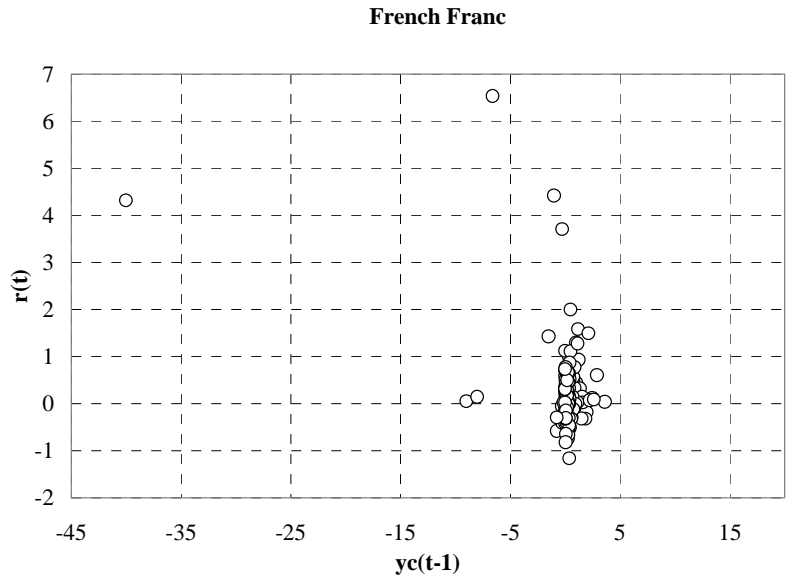

French Franc

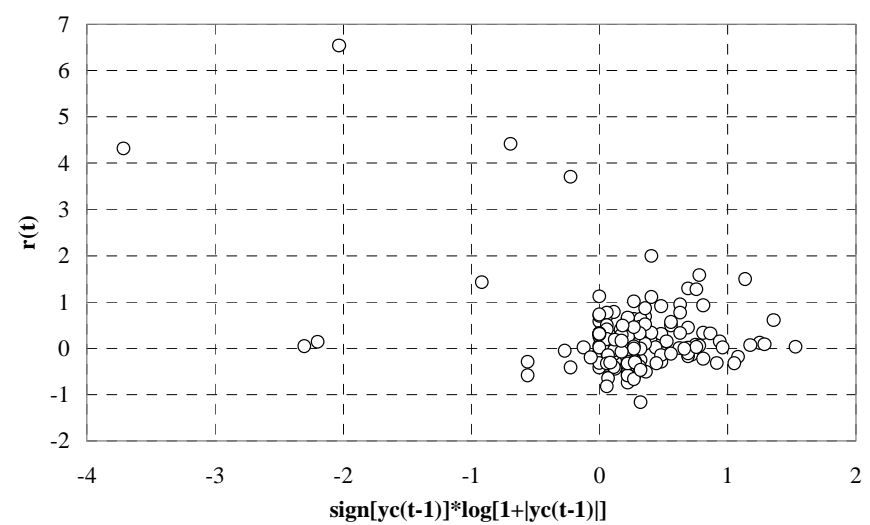

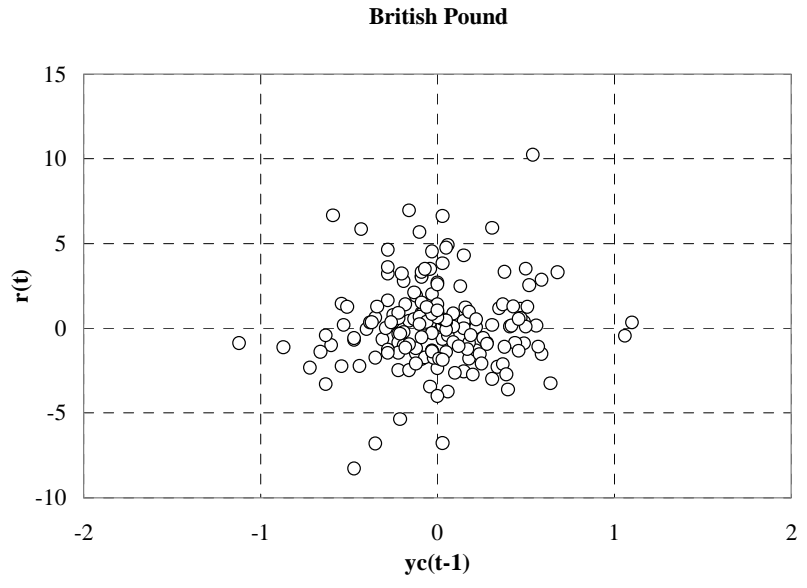

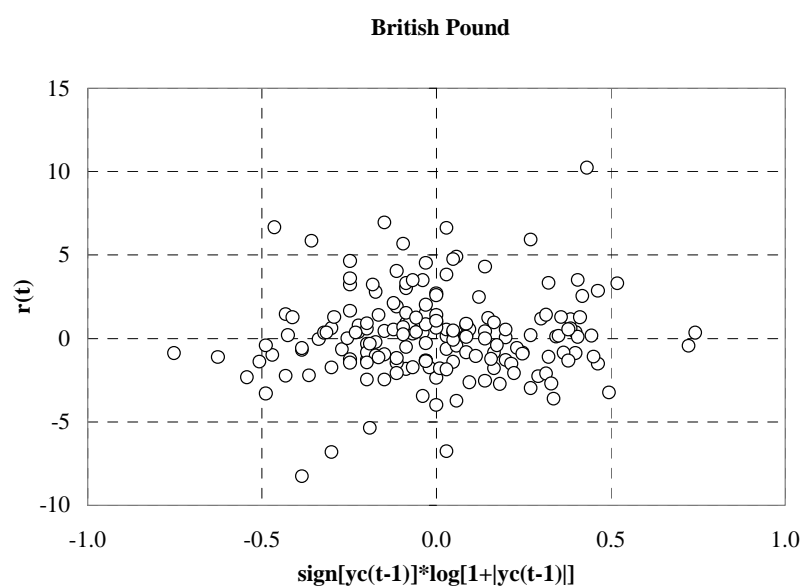


Figure 2: Averages of Implied Volatility US\$/FF Options 1992 and 1993

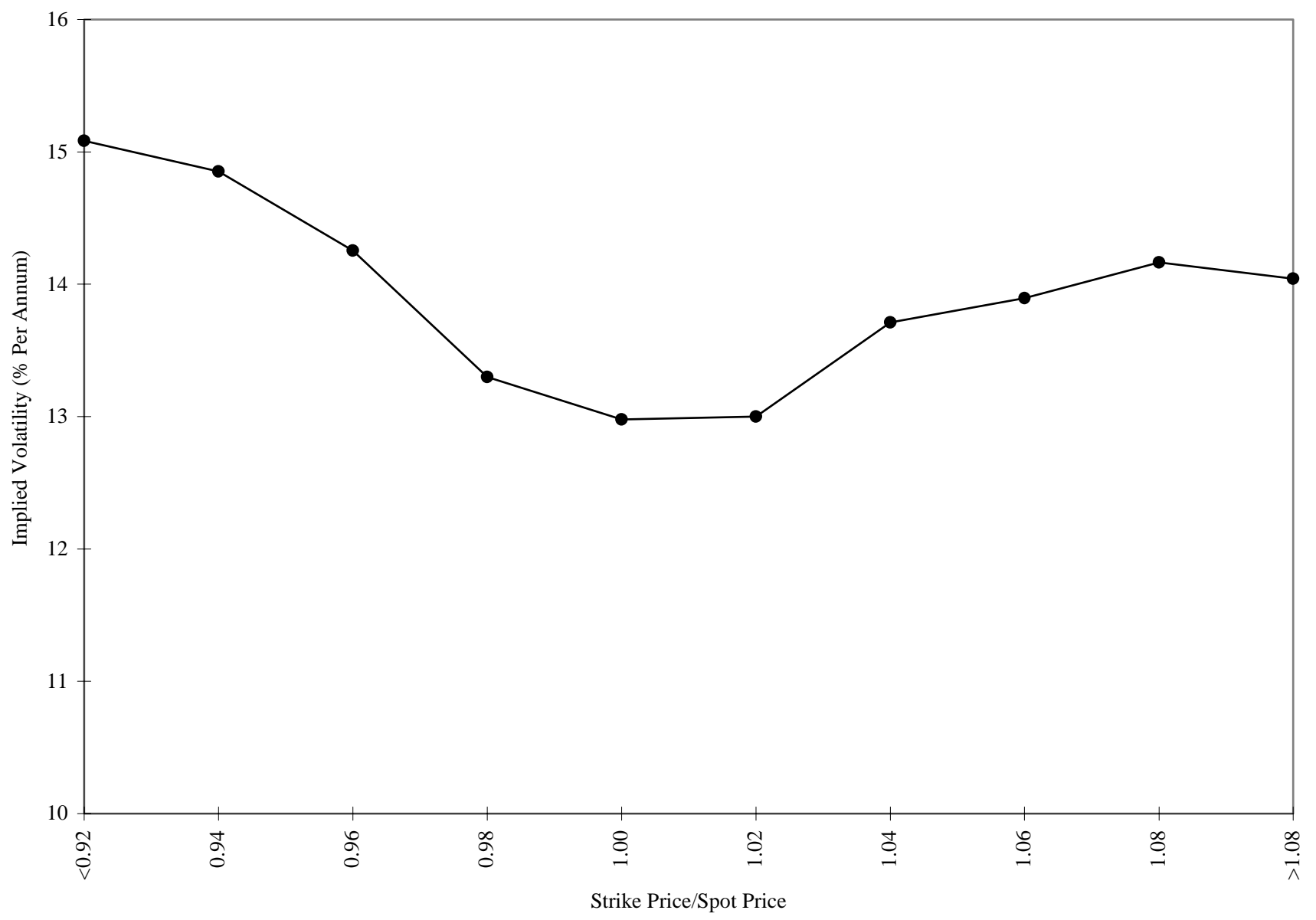


Figure 3: Averages of Implied Volatility US\$/BP Options 1992 and 1993

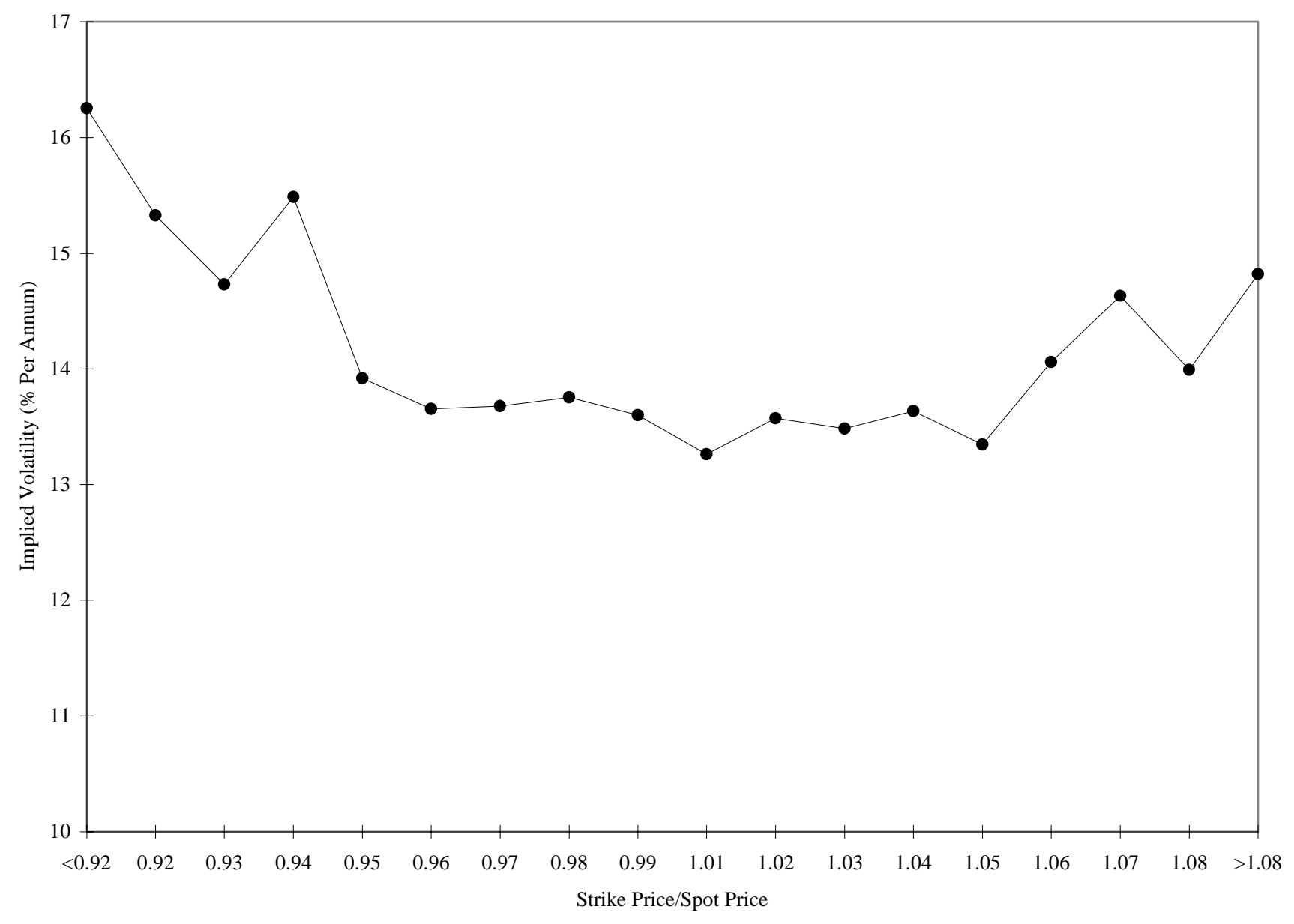


Figure 4: Options Market Risk of 3\% Devaluation in the FF: January-August 1993

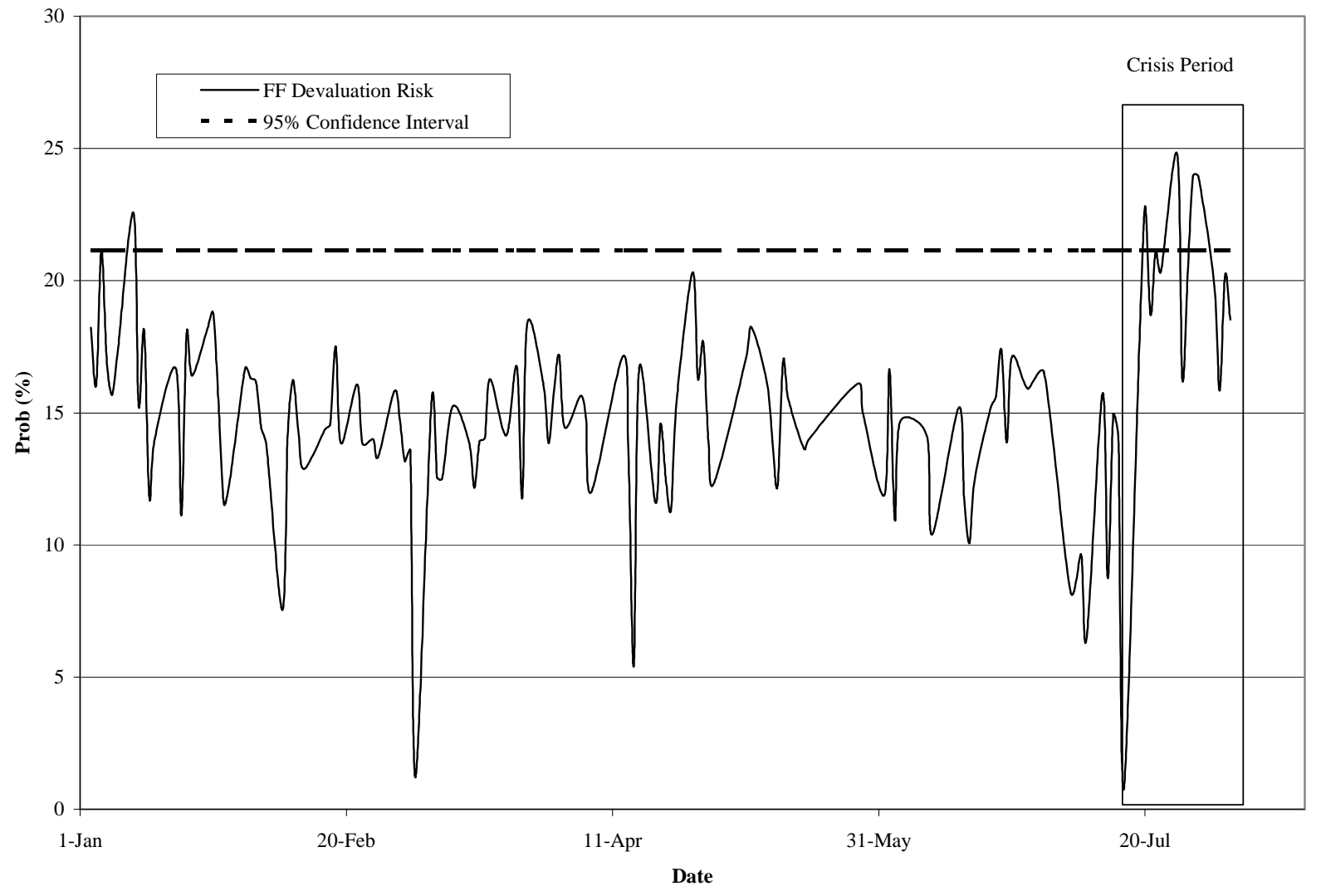


Figure 5: Options Market Risk of 3\% Devaluation in the FF During ERM Crisis: July-August 1993

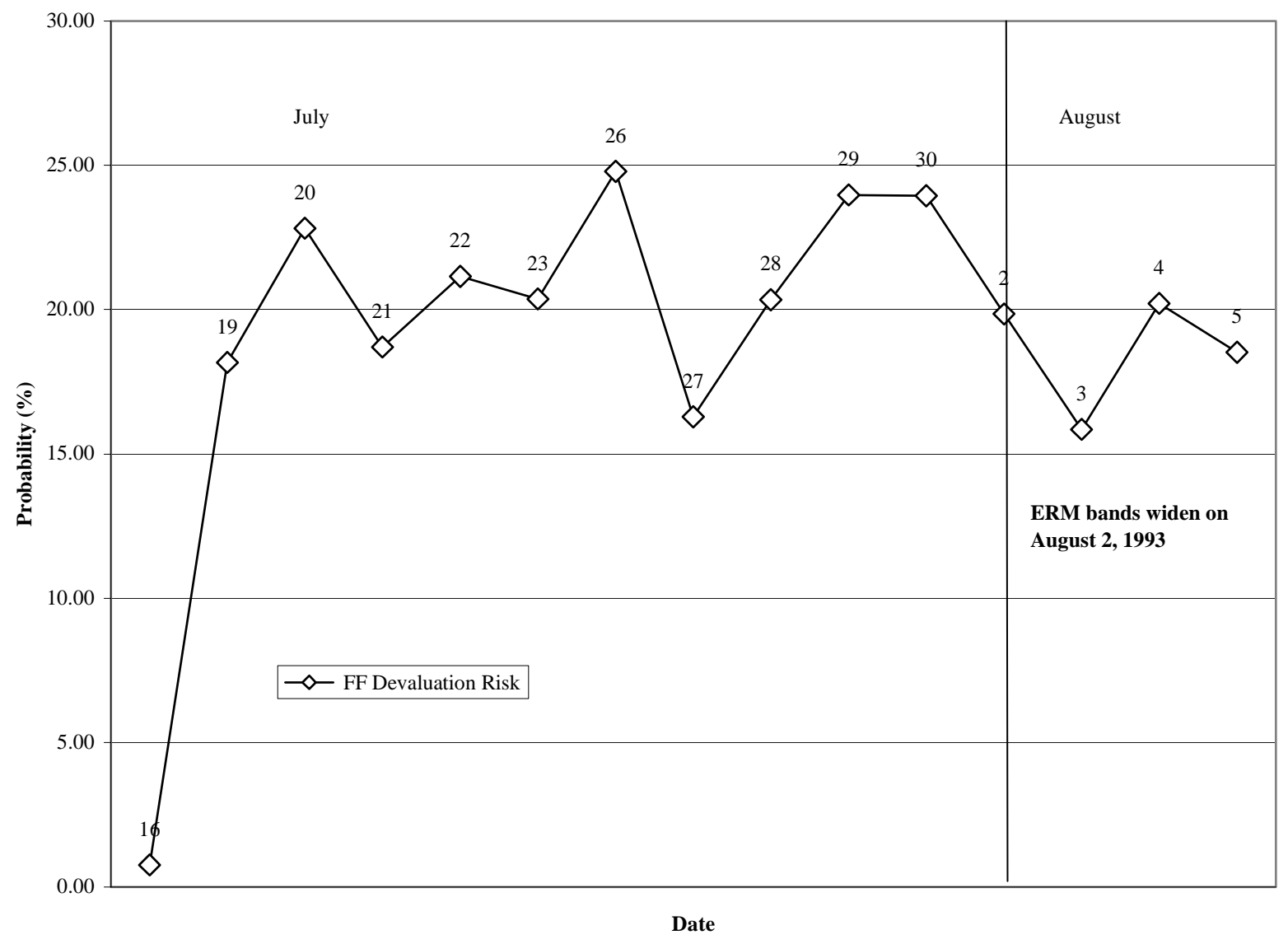


Figure 6: Options Market Risk of 3\% Devaluation in the BP: January-September 1992

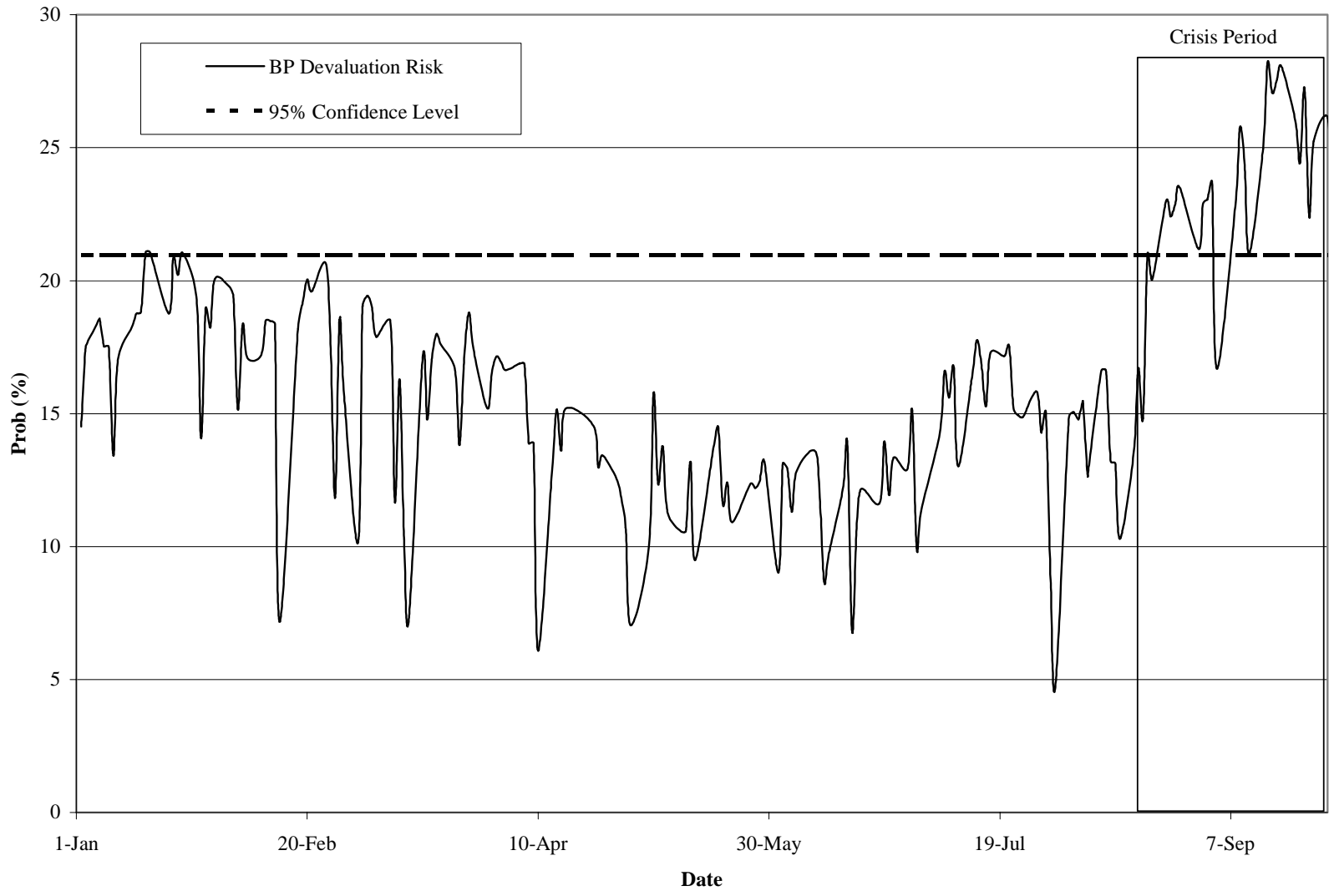


Figure 7: Options Market Risk of 3\% Devaluation in BP During ERM Crisis August-September 1992

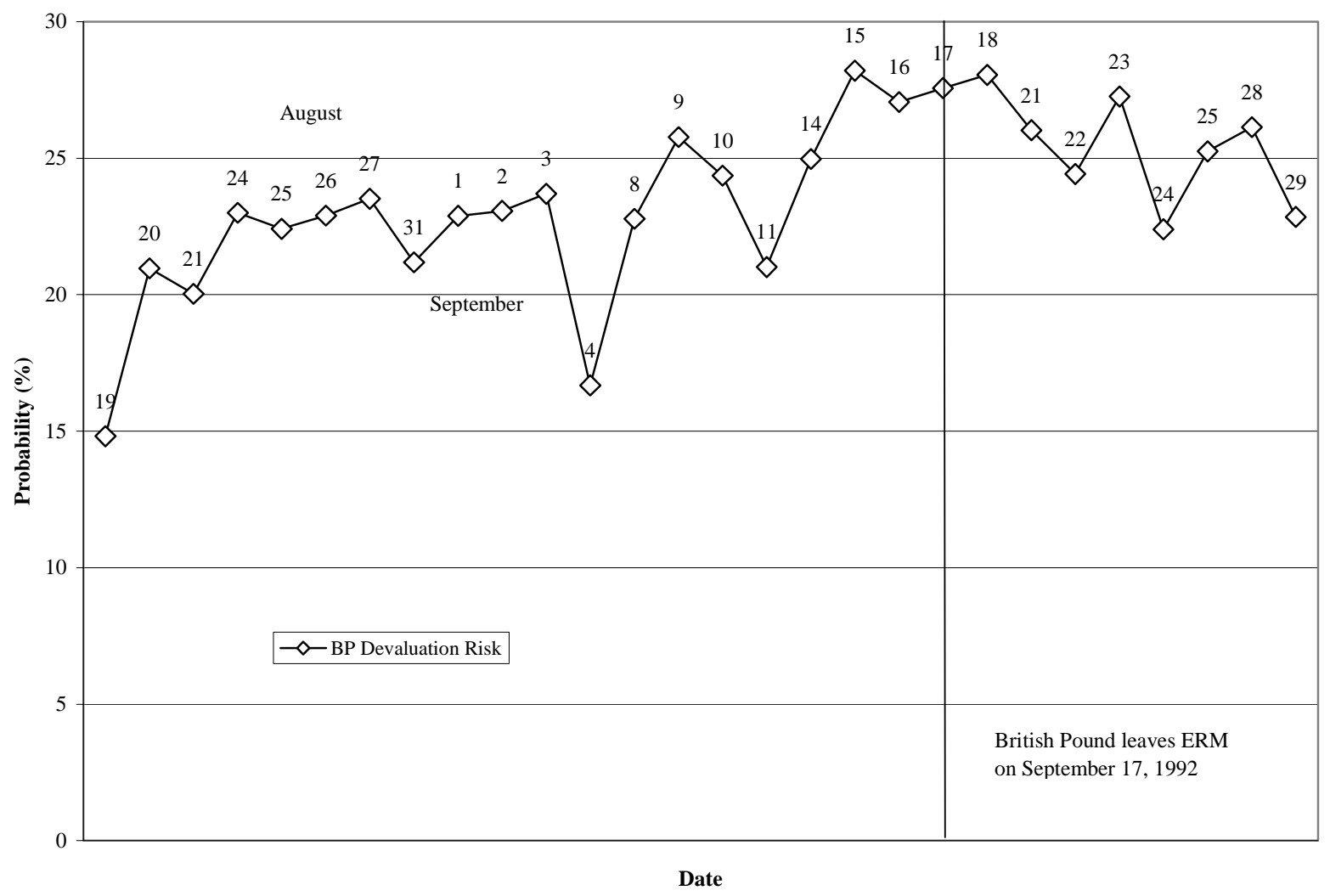


Figure 8: Spot Market Density Predictions for the FF. The Figure depicts the predicted densities for the FF from July 21 and July 30, 1993 (top panel), probability weighted components (middle) and raw components (bottom).
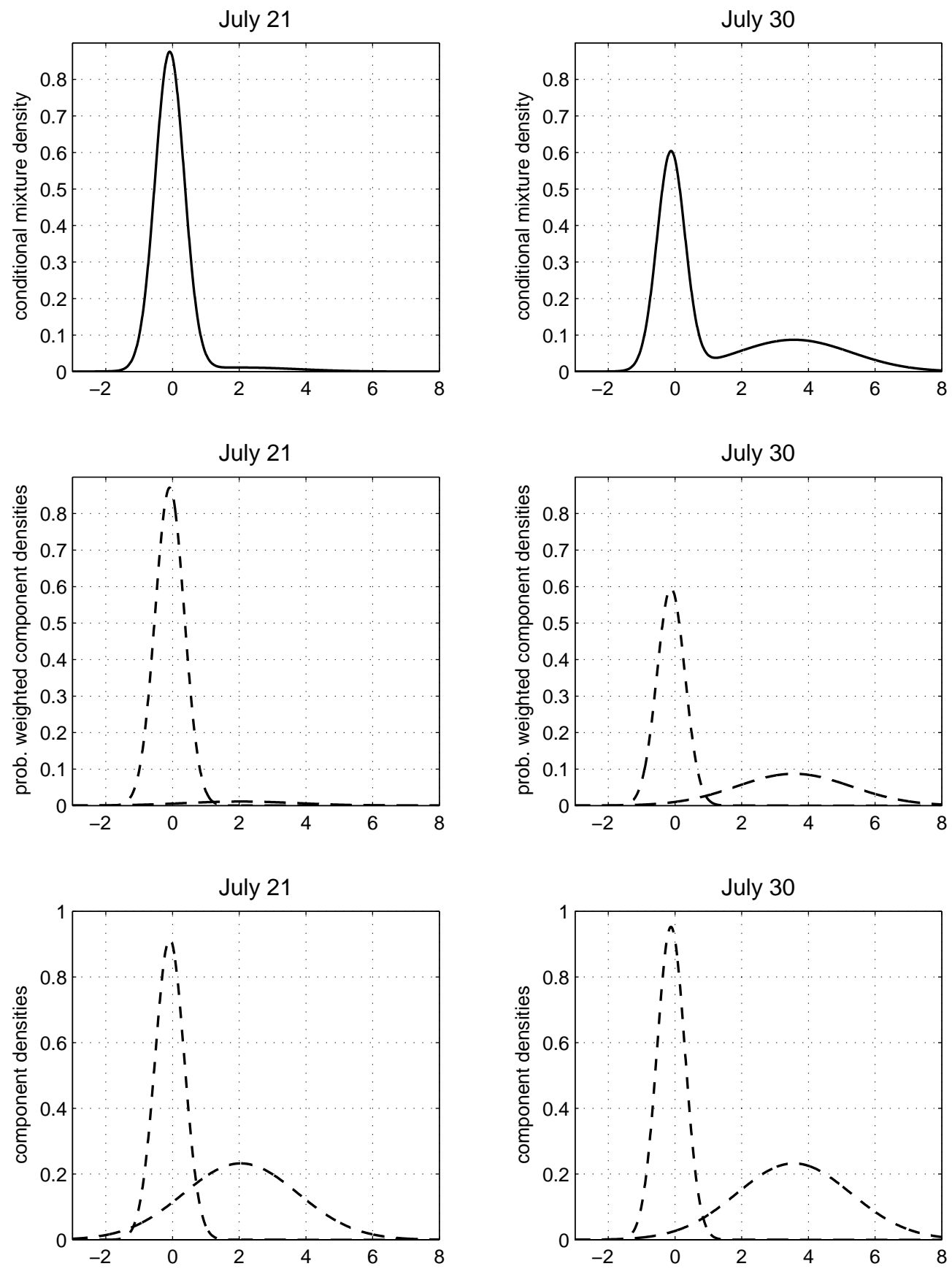
Figure 9: Spot Market Risk of 3\% Devaluation in the FF: January-August 1993

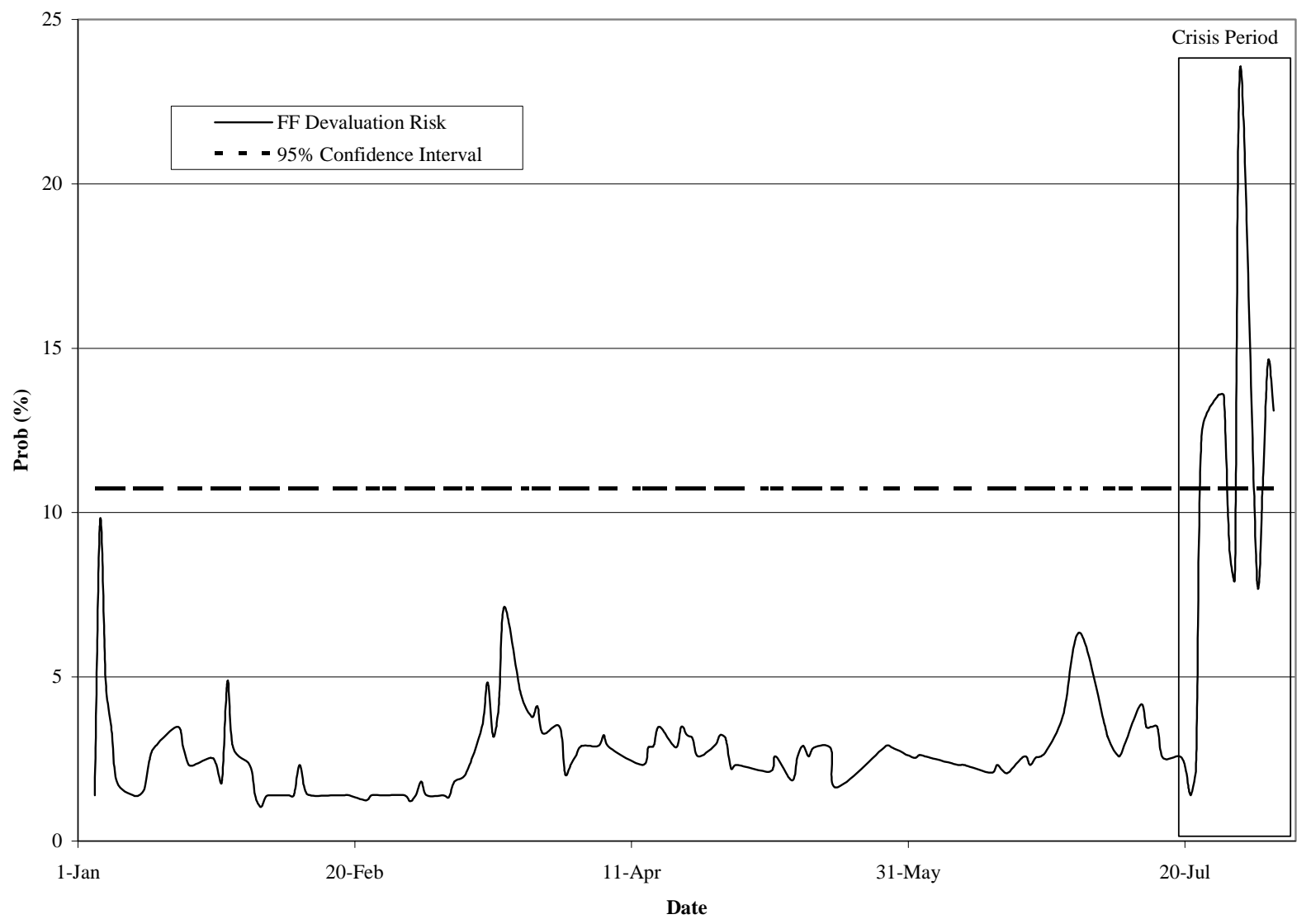


Figure 10: Spot Market Risk of 3\% Devaluation in the FF During ERM Crisis: July-August 1993

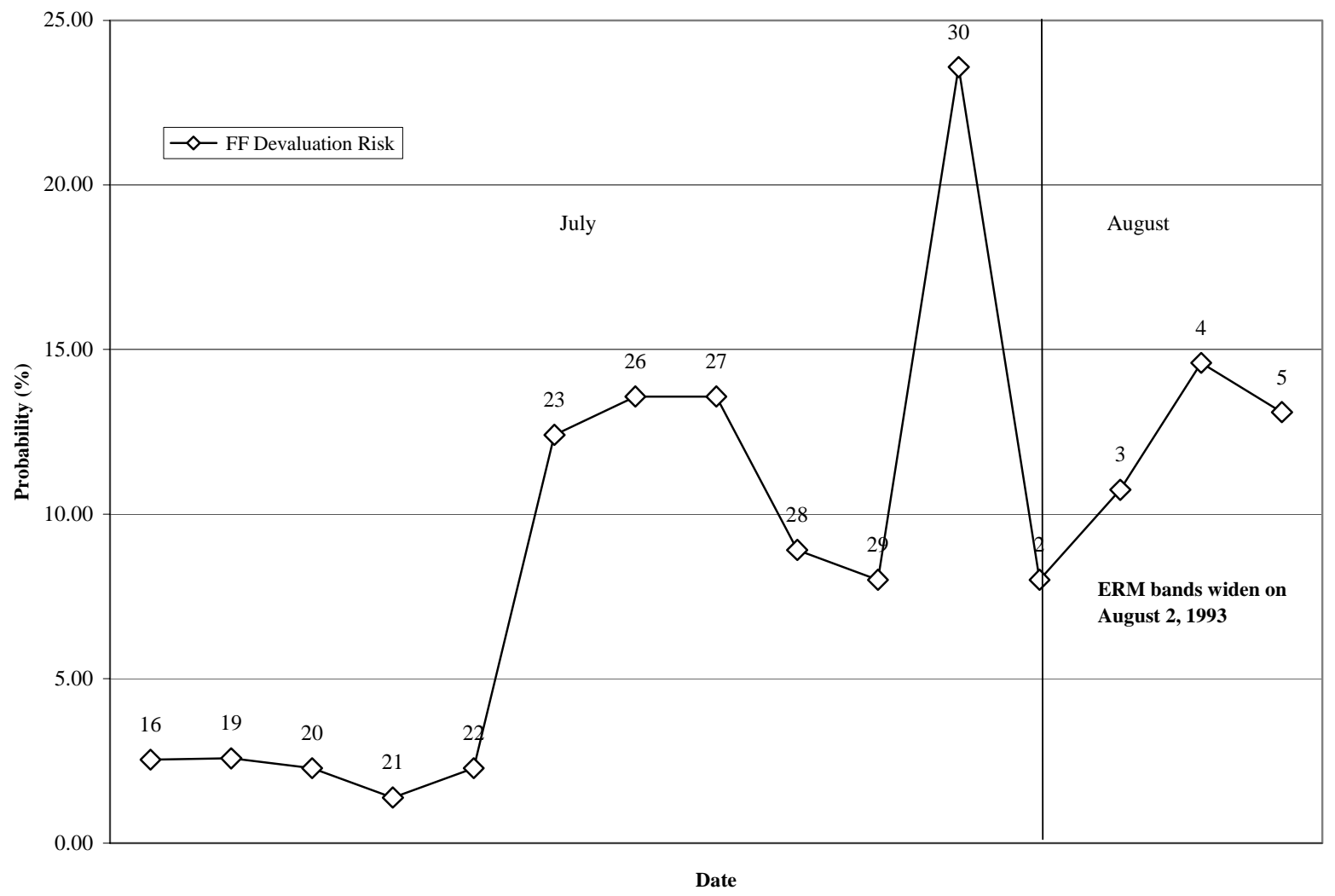


Figure 11: Spot Market Density Predictions for the BP. The Figure depicts the predicted densities for the BP from September 16 and September 21, 1992 (top panel), probability weighted components (middle) and raw components (bottom).
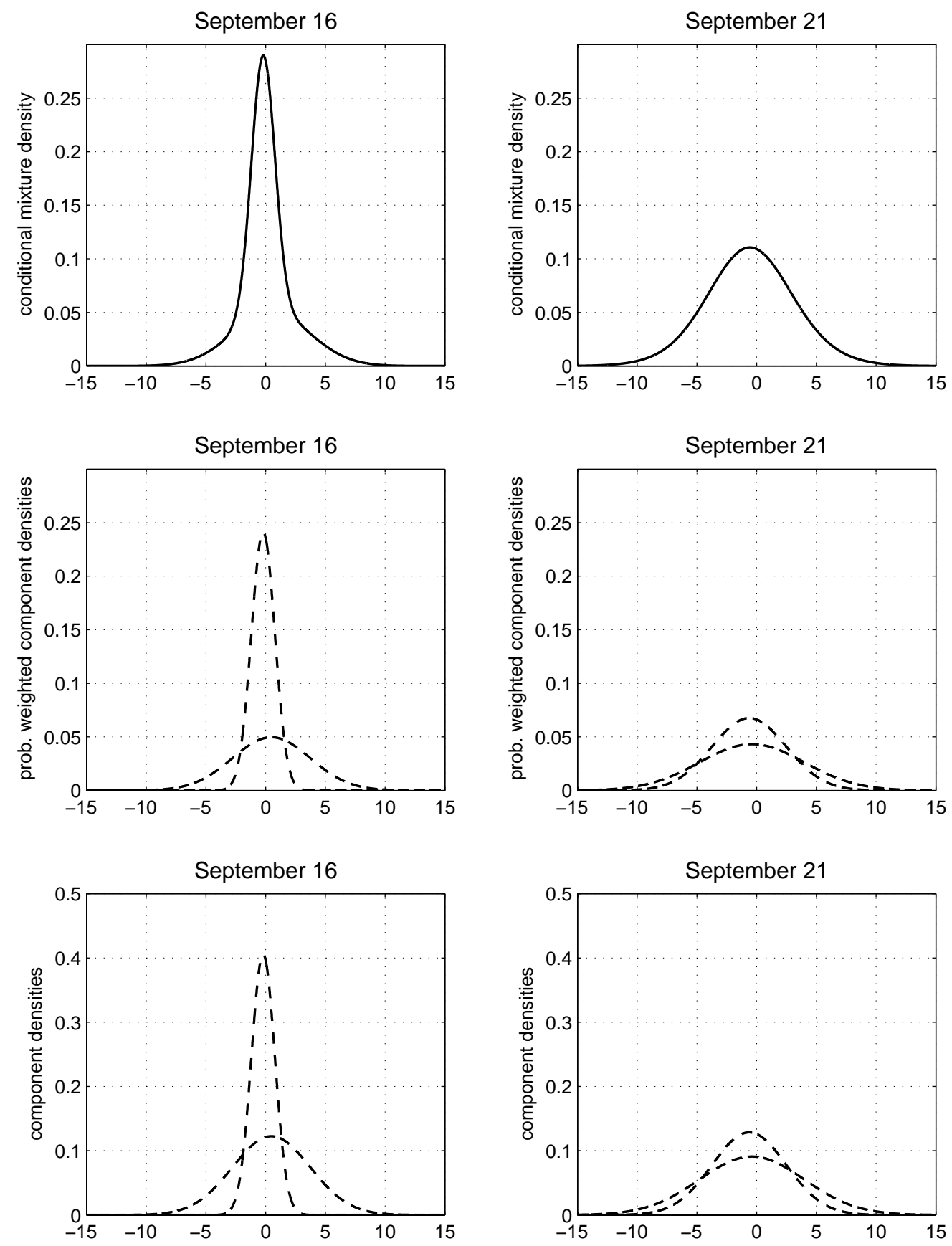
Figure 12: Spot Market Risk of 3\% Devaluation in the BP: January-September 1992

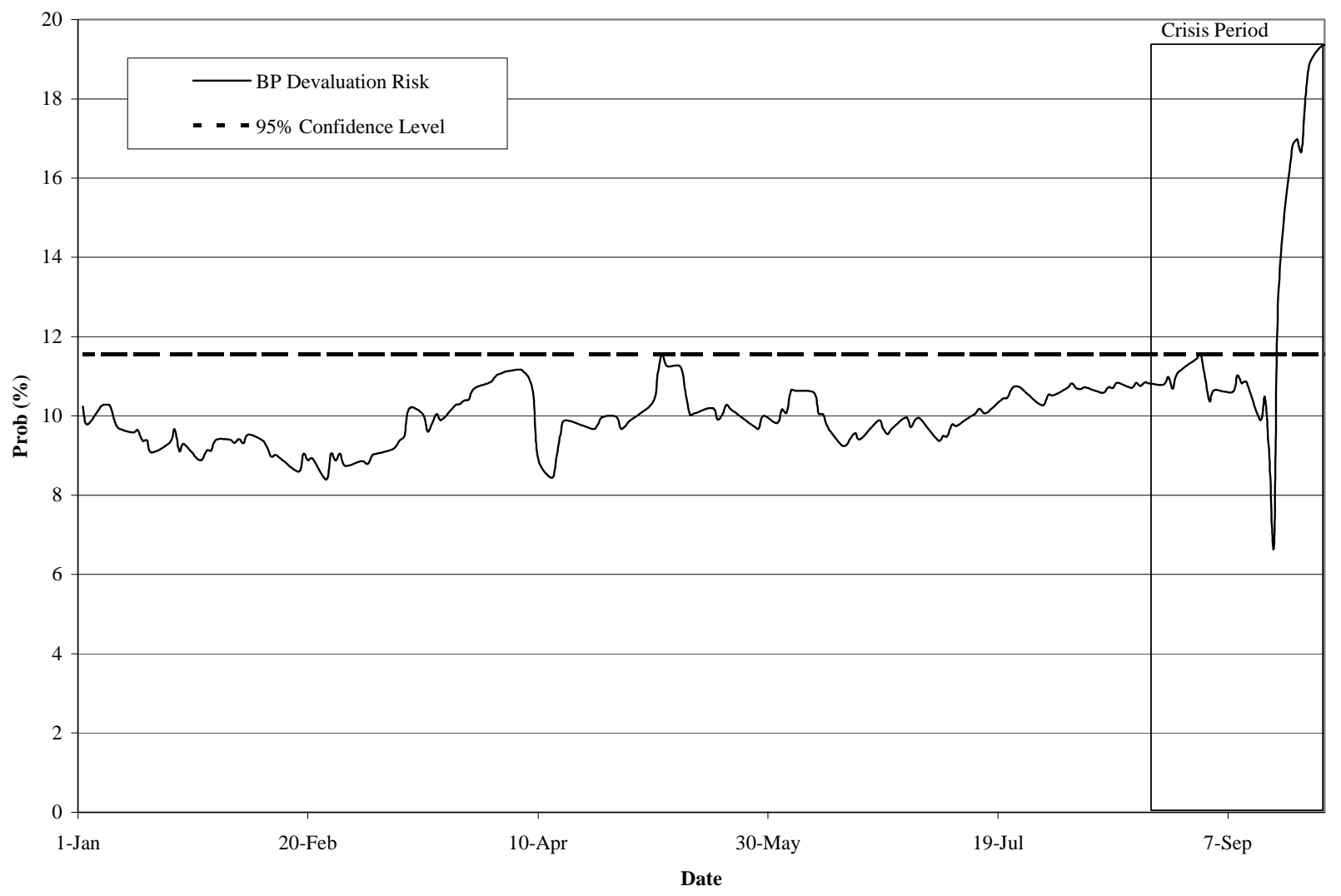


Figure 13: Spot Market Risk of 3\% Devaluation in the BP During EMS Crisis: August-September 1992

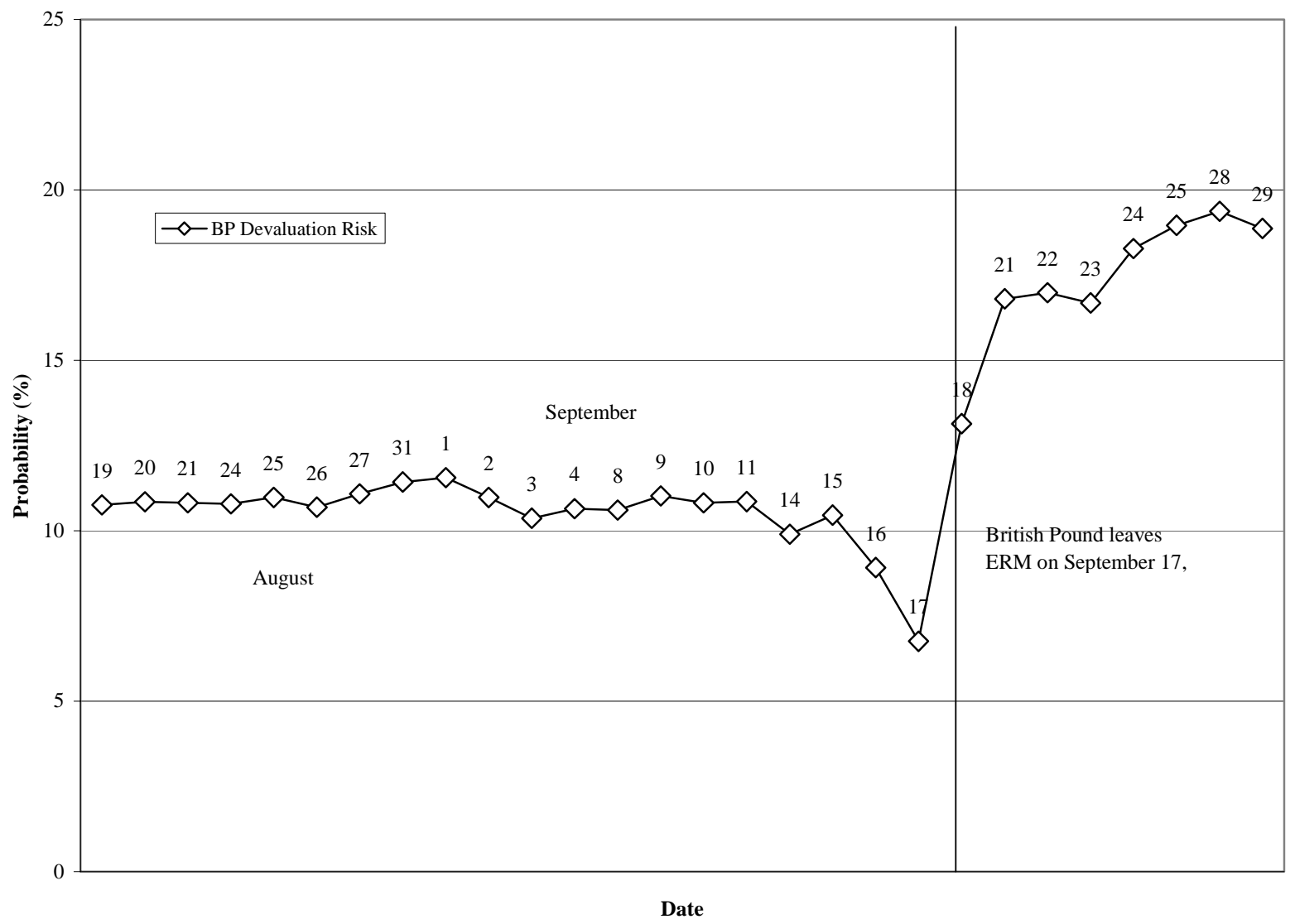




\section{CFS Working Paper Series:}

\begin{tabular}{|c|c|c|}
\hline No. & Author(s) & Title \\
\hline $2004 / 25$ & $\begin{array}{l}\text { Eberhard Feess } \\
\text { Ulrich Hege }\end{array}$ & $\begin{array}{l}\text { The Basel II Accord: Internal Ratings } \\
\text { and Bank Differentiation }\end{array}$ \\
\hline $2005 / 01$ & $\begin{array}{l}\text { David E. Lindsey } \\
\text { Athanasios Orphanides } \\
\text { Robert H. Rasche }\end{array}$ & $\begin{array}{l}\text { The Reform of October 1979: How It Happened } \\
\text { and Why }\end{array}$ \\
\hline $2005 / 02$ & $\begin{array}{l}\text { Torben G. Andersen } \\
\text { Tim Bollerslev } \\
\text { Peter F. Christoffersen } \\
\text { Francis X. Diebold }\end{array}$ & $\begin{array}{l}\text { Practical Volatility and Correlation Modeling for } \\
\text { Financial Market Risk Management }\end{array}$ \\
\hline $2005 / 03$ & $\begin{array}{l}\text { Francis X. Diebold } \\
\text { Monika Piazzesi } \\
\text { Glenn D. Rudebusch }\end{array}$ & $\begin{array}{l}\text { Modeling Bond Yields in Finance and } \\
\text { Macroeconomics }\end{array}$ \\
\hline $2005 / 04$ & $\begin{array}{l}\text { Torben G. Andersen } \\
\text { Tim Bollerslev } \\
\text { Francis X. Diebold } \\
\text { Jin (Ginger) Wu }\end{array}$ & $\begin{array}{l}\text { A Framework for Exploring the Macroeconomic } \\
\text { Determinants of Systematic Risk }\end{array}$ \\
\hline $2005 / 05$ & Jan Pieter Krahnen & $\begin{array}{l}\text { Der Handel von Kreditrisiken: Eine neue } \\
\text { Dimension des Kapitalmarktes }\end{array}$ \\
\hline $2005 / 06$ & $\begin{array}{l}\text { Günter Franke } \\
\text { Jan Pieter Krahnen }\end{array}$ & $\begin{array}{l}\text { Default Risk Sharing Between Banks and Markets: } \\
\text { The Contribution of Collateralized Debt } \\
\text { Obligations }\end{array}$ \\
\hline $2005 / 07$ & $\begin{array}{l}\text { Dirk Krueger } \\
\text { Harald Uhlig }\end{array}$ & $\begin{array}{l}\text { Competitive Risk Sharing Contracts with One- } \\
\text { Sided Commitment }\end{array}$ \\
\hline $2005 / 08$ & $\begin{array}{l}\text { Torben G. Andersen } \\
\text { Tim Bollerslev } \\
\text { Peter F. Christoffersen } \\
\text { Francis X. Diebold }\end{array}$ & Volatility Forecasting \\
\hline $2005 / 09$ & $\begin{array}{l}\text { Markus Haas } \\
\text { Stefan Mittnik } \\
\text { Bruce Mizrach }\end{array}$ & $\begin{array}{l}\text { Assessing Central Bank Credibility During the } \\
\text { ERM Crises: Comparing Option and Spot Market- } \\
\text { Based Forecasts }\end{array}$ \\
\hline
\end{tabular}

Copies of working papers can be downloaded at http://www.ifk-cfs.de 